\title{
Hypoxia-Ischemia During a Neonatal Sensitive Period Alters Purkinje Neuron Dendritic Complexity Differently in Male and Female Rats
}

Sheryl E Arambula ( $\square$ arambulasheryl@gmail.com )

University of Maryland, Baltimore

Miguel Perez-Pouchoulen

University of Maryland, Baltimore

Jaylyn Waddell

University of Maryland, Baltimore

Andressa Rejani Ribeiro Leite

São Paulo State University

Emily L Graham

University of Maryland, Baltimore

Amir A Mehrabani-Tabari

University of Maryland, Baltimore

Margaret M McCarthy

University of Maryland, Baltimore

\section{Research Article}

Keywords: Hypoxia-ischemia (HI), Neonatal Sensitive Period, Purkinje Neuron Dendritic Complexity, Male and Female Rats, brain injury

Posted Date: January 7th, 2022

DOI: https://doi.org/10.21203/rs.3.rs-1138932/v1

License: (c) (1) This work is licensed under a Creative Commons Attribution 4.0 International License. Read Full License 


\section{Abstract}

Perinatal hypoxia-ischemia $(\mathrm{HI})$ is a major health issue with no effective therapies beyond head cooling. Notably, male infants are at a greater risk for $\mathrm{HI}$ and exhibit more extreme deficits than females. Extensive clinical evidence indicates that perinatal $\mathrm{HI}$ impacts the developing cerebellum, yet this region has been largely ignored in preclinical models. Using a modified version of the Rice-Vannucci rat model for HI injury at postnatal day 10, we find reductions in dendritic complexity of Purkinje neurons in males one week later. Females exhibited modest but opposite effects, with slight increases in dendritic complexity, based on Sholl analysis. A custom-made NanoString panel for quantifying mRNAs associated with development, inflammation, and sex differences found almost no commonality in the response to $\mathrm{HI}$ in males versus females, with males up-regulating genes associated with microglia activity whereas females increased expression of a protective complement protein, but also of enzymes associated with endocannabinoids and prostaglandins. Both sexes exhibited a reduction in the GABA-synthetic enzymes, GAD-65 and GAD-67, after $\mathrm{HI}$, suggesting increased excitotoxicity, but why males suffered more damage to the Purkinje neurons is unknown.

\section{Introduction}

Hypoxia-ischemia $(\mathrm{HI})$ is the most common cause of brain injury in term infants that experience birth complications (e.g., abnormal presentation, placental disruption, umbilical cord compression, etc. $)^{1}$. Globally, intrapartum-related perinatal $\mathrm{HI}$ is responsible for 0.7-1.6 million deaths each year and remains the major cause of infant mortality and long-term morbidity, particularly in communities lacking access to advanced obstetrics ${ }^{2}$. The prognosis following perinatal $\mathrm{HI}$ in full-term infants depends on the intensity and duration of the insult. Infants with moderate or severe HI often die or develop lifelong motor, cognitive, and behavioral impairments, whereas those with mild $\mathrm{HI}$ often exhibit subtle cognitive and behavioral deficits later in life ${ }^{3}$.

Biological sex is both a risk factor and a prognostic factor for the consequences of perinatal $\mathrm{HI}$. Among term infants, males have a greater incidence of $\mathrm{HI}^{4,5}$ and poorer recovery and worse long-term outcomes relative to females with equivalent $\mathrm{HI}$ insults ${ }^{6,7}$. Despite this clear gender bias in frequency and severity, there remains a significant gap in understanding the biological origins of sex differences in outcome following perinatal HI. Greater susceptibility in males is likely mediated by a combination of factors including the organizational effects of androgens produced by the fetal testis during gestation, divergent cell death pathways in females and males, and sex differences in inflammatory signaling at homeostasis and after injury ${ }^{8-10}$.

Beyond sex differences, there remains an additional, substantial gap in our understanding of the selective vulnerability of different regions of the brain to perinatal HI. The cerebellum has long been thought to be relatively spared from $\mathrm{HI}$ injury because it is not directly affected by ischemia due to the preferential shunting of blood flow to the vertebrobasilar system during hypoxia ${ }^{11,12}$. Over the last two decades, however, advances in magnetic resonance imaging have enabled the detection of subtle microstructural 
features and transformed our understanding of perinatal $\mathrm{HI}{ }^{13,14}$. Clinical studies increasingly find profound yet diffuse injury leading to impaired development of the cerebellum ${ }^{15,16}$. Further, many of the long-term deficits induced by perinatal $\mathrm{HI}$ overlap the domain-specific cognitive and motor deficits associated with cerebellar injury ${ }^{17}$. Despite this robust clinical evidence, the cellular impact of perinatal $\mathrm{HI}$ on the cerebellum remains largely under-investigated in animal models, especially with respect to sexrelated differences.

A unique feature of the cerebellum is its prolonged developmental trajectory as it is one of the first brain structures to differentiate and one of the last to fully mature. This makes it particularly vulnerable to insults during development. A substantial fraction of cerebellar development occurs postnatally in mammals, including neuronal proliferation, neuronal migration, apoptosis, and dendritic spine and synapse formation ${ }^{18-20}$. This sensitive developmental period extends into the second postnatal year in humans and occurs during the first weeks of life in rodents ${ }^{21,22}$. A sensitive period to inflammation in the postnatal cerebellum that corresponds to the time around birth in humans, the time of greatest risk for $\mathrm{HI}$, has been described for the laboratory rat ${ }^{23-25}$.

In the present study, the impact of perinatal HI was assessed with attention to whether it would impair cerebellar development in a sex-dependent manner and lead to histopathological abnormalities at the cellular level. A well-established Sprague-Dawley rat model of moderate HI brain injury occurring at postnatal day 10 (PN10), was used to evaluate cerebellar development 7 days post-injury (PN17) in males and females. To analyze the impact of $\mathrm{HI}$ on Purkinje neuron branching in more detail, we used a virus expressing eGFP to sparsely label Purkinje neurons. In males only, perinatal HI reduced Purkinje dendritic arbor complexity, such that the dendritic tree branched less frequently. Using a targeted, custom gene-expression array, we found altered expression of genes related to the phagocytic activity of microglia in the male cerebellar vermis, while genes related to the endocannabinoid system and hormone synthesis were upregulated in females. We then used western blot to measure the impact of $\mathrm{HI}$ on protein markers for the predominant cell types and neurotransmitters in the cerebellum. Glutamic acid decarboxylase (GAD) expression was reduced in the anterior vermis, suggesting that perinatal $\mathrm{HI}$ reduces GABAergic signaling. Immunohistochemistry for the major cell types in the cerebellum showed no changes in the number or density of Purkinje neurons, astrocytes, or microglia. Implicated pathways and cell types will inform future research into neuropathogenesis induced by perinatal $\mathrm{HI}$.

\section{Results}

\section{Perinatal $\mathrm{HI}$ reduces Purkinje neuron dendritic arborization in males only}

Central vermis ( $\mathrm{VVla}$ ): To test the dendritic locations at which $\mathrm{HI}$ had the greatest effect on Purkinje neurons, Sholl analysis was performed and compared between groups (See Fig. 1a for representative confocal images of Purkinje neurons). Two cohorts were analyzed, each by separate investigators 
blinded to treatment and sex (See Supplementary Fig. 1 online) to replicate the data. The data were then combined and analyzed across cohorts. HI significantly altered dendritic arborization in Purkinje neurons in a sex-dependent manner (main effect of distance $p<0.0001$, sex $X$ treatment interaction $p=0.017$, distance $X$ treatment $X$ sex interaction $p=0.001$ ). Sholl analysis showed a clear decrease in the dendritic branching of Purkinje neurons in males after HI compared to same-sex sham controls (Fig. 1b). The highest number of intersections were observed within 50-130 $\mu \mathrm{m}$ from the center of the cell soma. In $\mathrm{HI}$ males, the number of dendritic branches was markedly reduced in this intermediate region (80-130 $\mu \mathrm{m}$ from soma; Table 1). Intriguingly, $\mathrm{HI}$ in females significantly increased proximal dendritic intersections (20-70 $\mu \mathrm{m}$ from soma; Table 1) and decreased distal dendritic intersections (140-150 $\mu \mathrm{m}$ from soma; $p=$ 0.009 and $p=0.025$ ), when compared to female controls (Fig. 1b). Hl-induced dendritic alterations were prominent and diverged between sex, with $\mathrm{HI}$ males exhibiting marked suppression of Purkinje cell dendritic outgrowth compared to HI females (70-100 and $120 \mu \mathrm{m}$ from soma; Table 1; Fig. 1c). Lastly, sex differences between sham groups were discordant. Sham males had more dendritic intersections than sham females at $60 \mu \mathrm{m}$ from the soma $(p=0.004)$ but fewer dendritic intersections at 140 and $160 \mu \mathrm{m}$ from the soma ( $p=0.031$ and $p=0.041$, respectively; Fig. $1 c)$. 
Table 1

Sholl analysis of Purkinje neuron dendritic arborization in vermal Lobule LVla of Sham and HI male and female rats.

\begin{tabular}{|c|c|c|c|c|c|}
\hline \multirow{2}{*}{$\begin{array}{l}\text { Fig. } \\
\text { Panel }\end{array}$} & \multirow[t]{2}{*}{ Statistical Test } & \multirow[t]{2}{*}{ Conditions } & \multicolumn{3}{|l|}{ Results } \\
\hline & & & $\begin{array}{l}\text { test } \\
\text { value }\end{array}$ & $\begin{array}{l}p- \\
\text { value }\end{array}$ & $\begin{array}{l}95 \% \\
\text { Cl/Effect } \\
\text { size }\end{array}$ \\
\hline $1 b$ & unpaired t-test & $\begin{array}{l}\text { LVla Sholl; } 80 \mu \mathrm{m} \text { : MHI vs } \\
\text { MSham }\end{array}$ & $\begin{array}{l}\mathrm{t}(253) \\
=2.9\end{array}$ & 0.004 & 0.15 \\
\hline $1 b$ & unpaired t-test & $\begin{array}{l}\text { LVla Sholl; } 90 \text { m: MHI vs } \\
\text { MSham }\end{array}$ & $\begin{array}{l}\mathrm{t}(253) \\
=3.5\end{array}$ & $<0.001$ & 0.16 \\
\hline $1 b$ & unpaired t-test & $\begin{array}{l}\text { LVla Sholl; } 100 \text { um: MHI vs } \\
\text { MSham }\end{array}$ & $\begin{array}{l}\mathrm{t}(253) \\
=4.4\end{array}$ & $<0.001$ & 0.18 \\
\hline $1 b$ & unpaired t-test & $\begin{array}{l}\text { LVla Sholl; } 110 \mu \mathrm{m} \text { : MHI vs } \\
\text { MSham }\end{array}$ & $\begin{array}{l}\mathrm{t}(253) \\
=3.3\end{array}$ & $<0.001$ & 0.16 \\
\hline $1 b$ & unpaired t-test & $\begin{array}{l}\text { LVla Sholl; } 120 \text { um: MHI vs } \\
\text { MSham }\end{array}$ & $\begin{array}{l}\mathrm{t}(253) \\
=2.4\end{array}$ & 0.016 & 0.13 \\
\hline $1 b$ & unpaired t-test & $\begin{array}{l}\text { LVla Sholl; } 130 \mu \mathrm{m} \text { : MHI vs } \\
\text { MSham }\end{array}$ & $\begin{array}{l}\mathrm{t}(253) \\
=2.1\end{array}$ & 0.038 & 0.12 \\
\hline $1 b$ & unpaired t-test & LVla Sholl; $30 \mu \mathrm{m}$ : FHI vs FSham & $\begin{array}{l}t(276) \\
=2.0\end{array}$ & 0.049 & 0.12 \\
\hline $1 b$ & unpaired t-test & LVla Sholl; $40 \mu \mathrm{m}$ : FHI vs FSham & $\begin{array}{l}\mathrm{t}(276) \\
=2.8\end{array}$ & 0.005 & 0.14 \\
\hline $1 b$ & unpaired t-test & LVla Sholl; 50 m: FHI vs FSham & $\begin{array}{l}\mathrm{t}(276) \\
=2.9\end{array}$ & 0.003 & 0.14 \\
\hline $1 b$ & unpaired t-test & LVla Sholl; $60 \mu \mathrm{m}$ : FHI vs FSham & $\begin{array}{l}\mathrm{t}(276) \\
=3.4\end{array}$ & $<0.001$ & 0.15 \\
\hline $1 b$ & unpaired t-test & LVla Sholl; $70 \mu \mathrm{m}$ : FHI vs FSham & $\begin{array}{l}\mathrm{t}(276) \\
=2.8\end{array}$ & 0.005 & 0.14 \\
\hline $1 b$ & unpaired t-test & $\begin{array}{l}\text { LVla Sholl; } 140 \mu \mathrm{m} \text { : FHI vs } \\
\text { FSham }\end{array}$ & $\begin{array}{l}t(276) \\
=2.0\end{array}$ & 0.009 & 0.12 \\
\hline $1 b$ & unpaired t-test & $\begin{array}{l}\text { LVla Sholl; } 150 \mu \mathrm{m} \text { : FHI vs } \\
\text { FSham }\end{array}$ & $\begin{array}{l}t(276) \\
=2.3\end{array}$ & 0.025 & 0.12 \\
\hline $1 c$ & unpaired t-test & $\begin{array}{l}\text { LVla Sholl; } 60 \mu \mathrm{m} \text { : FSham vs } \\
\text { MSham }\end{array}$ & $\begin{array}{l}\mathrm{t}(276) \\
=2.9\end{array}$ & 0.004 & 0.14 \\
\hline $1 c$ & unpaired t-test & $\begin{array}{l}\text { LVla Sholl; } 140 \mu \mathrm{m} \text { : FSham vs } \\
\text { MSham }\end{array}$ & $\begin{array}{l}\mathrm{t}(276) \\
=2.2\end{array}$ & 0.031 & 0.12 \\
\hline $1 c$ & unpaired t-test & $\begin{array}{l}\text { LVla Sholl; } 160 \mu \mathrm{m} \text { : FSham vs } \\
\text { MSham }\end{array}$ & $\begin{array}{l}t(276) \\
=2.0\end{array}$ & 0.041 & 0.12 \\
\hline
\end{tabular}




\begin{tabular}{|c|c|c|c|c|c|}
\hline \multirow{2}{*}{$\begin{array}{l}\text { Fig. } \\
\text { Panel }\end{array}$} & \multirow[t]{2}{*}{ Statistical Test } & \multirow[t]{2}{*}{ Conditions } & \multicolumn{3}{|l|}{ Results } \\
\hline & & & $\begin{array}{l}\text { test } \\
\text { value }\end{array}$ & $\begin{array}{l}p- \\
\text { value }\end{array}$ & $\begin{array}{l}95 \% \\
\text { Cl/Effect } \\
\text { size }\end{array}$ \\
\hline $1 c$ & unpaired t-test & LVla Sholl; $70 \mu \mathrm{m}$ : FHI vs MHI & $\begin{array}{l}\mathrm{t}(253) \\
=2.4\end{array}$ & 0.018 & 0.13 \\
\hline $1 c$ & unpaired t-test & LVla Sholl; 80 um: FHI vs MHI & $\begin{array}{l}\mathrm{t}(253) \\
=2.7\end{array}$ & 0.008 & 0.14 \\
\hline $1 c$ & unpaired t-test & LVla Sholl; $90 \mu \mathrm{m}$ : FHI vs MHI & $\begin{array}{l}t(253) \\
=3.0\end{array}$ & 0.003 & 0.15 \\
\hline $1 c$ & unpaired t-test & LVla Sholl; $120 \mu \mathrm{m}$ : FHI vs MHI & $\begin{array}{l}\mathrm{t}(253) \\
=2.5\end{array}$ & 0.014 & 0.14 \\
\hline $1 d$ & 2-way ANOVA & $\begin{array}{l}\text { LVla Avg. dendrite area; main } \\
\text { effect: sex }\end{array}$ & $\begin{array}{l}F(1,24) \\
=5.4\end{array}$ & 0.029 & $\begin{array}{l}{[-14} \\
-0.85]\end{array}$ \\
\hline $1 \mathrm{~g}$ & 2-way ANOVA & $\begin{array}{l}\text { LVla Total dendrite area; main } \\
\text { effect: sex }\end{array}$ & $\begin{array}{l}F(1,24) \\
=3.3\end{array}$ & 0.08 & $\begin{array}{l}{[-9767} \\
599]\end{array}$ \\
\hline $1 \mathrm{~h}$ & 2-way ANOVA & $\begin{array}{l}\text { LVla Total dendrite length; main } \\
\text { effect: treatment }\end{array}$ & $\begin{array}{l}F(1,24) \\
=4.3\end{array}$ & 0.048 & $\begin{array}{l}{[5.97} \\
1270]\end{array}$ \\
\hline $1 \mathrm{~h}$ & 2-way ANOVA & $\begin{array}{l}\text { LVla Total dendrite length; } \\
\text { interaction effect }\end{array}$ & $\begin{array}{l}F(1,24) \\
=7.7\end{array}$ & 0.01 & $\begin{array}{l}{[438} \\
2966]\end{array}$ \\
\hline $1 \mathrm{~h}$ & $\begin{array}{l}\text { Bonferroni's post hoc } \\
\text { comparison }\end{array}$ & $\begin{array}{l}\text { LVla Total dendrite length; MHI } \\
\text { vs MSham }\end{array}$ & NA & 0.013 & $\begin{array}{l}{[238,} \\
2741]\end{array}$ \\
\hline
\end{tabular}

Female pups consistently had a greater average dendrite area and total dendrite area than males (main effects of $\operatorname{sex} p=0.029$ and $p=0.08$, respectively), but there were no main effects of treatment or sex by treatment interactions (Fig. 1d, 1g). The average dendrite length was unaffected by $\mathrm{HI}$ or sex (Fig. 1e), but there was a main effect of treatment $(p=0.048)$ and a treatment by sex interaction $(p=0.014)$ primarily driven by a male-specific reduction in total dendrite length following $\mathrm{HI}(p=0.0134 ; \mathrm{Fig} .1 \mathrm{~h})$. The average number of dendrite segments was unaffected by $\mathrm{HI}$, sex, or an interaction between the two (Fig. 1f).

Nodular vermis $(L X)$ : Sholl analysis revealed $\mathrm{HI}$ altered Purkinje cell dendritic development in the nodular vermis (See Fig. 2a for representative confocal images of Purkinje neurons). In males perinatal HI caused a leftward shift in the Sholl curve compared to same-sex control conditions (Fig. 2b), resulting in an increase in the number of proximal dendrites (20-50 $\mu \mathrm{m}$ from soma; Table 2), the Sholl curve peaking markedly closer to the soma (40 vs $100 \mu \mathrm{m}$ from the soma), and a decrease in dendrites $90-120 \mu \mathrm{m}$ from the soma (Table 2). Like the central vermis, female Purkinje neurons in the nodular vermis had more proximal and medial dendrites following $\mathrm{HI}(20-70 \mu \mathrm{m}$ from soma; Table 2). Among sham groups (Fig. 2c), males had more medial dendritic intersections than females $(90-100 \mu \mathrm{m}$ from soma; $p=0.013$ and $p=0.031)$. $\mathrm{HI}$ males had significantly more dendrites at $40 \mu \mathrm{m}$ from the soma than $\mathrm{HI}$ females $(p=$ 
$0.027)$ and $\mathrm{HI}$ females had significantly more dendrites at 110 and $120 \mu \mathrm{m}$ from the soma $(p=0.031$ and $p=0.017)$. 
Table 2

Sholl analysis of Purkinje neuron dendritic arborization in vermal Lobule LX of Sham and HI male and female rats

\begin{tabular}{|c|c|c|c|c|c|}
\hline \multirow{2}{*}{$\begin{array}{l}\text { Fig. } \\
\text { Panel }\end{array}$} & \multirow{2}{*}{$\begin{array}{l}\text { Statistical } \\
\text { Test }\end{array}$} & \multirow[t]{2}{*}{ Conditions } & \multicolumn{3}{|l|}{ Results } \\
\hline & & & $\begin{array}{l}\text { test } \\
\text { value }\end{array}$ & $\begin{array}{l}p- \\
\text { value }\end{array}$ & $\begin{array}{l}\text { 95\% Cl/Effect } \\
\text { size }\end{array}$ \\
\hline $2 b$ & $\begin{array}{l}\text { unpaired } t- \\
\text { test }\end{array}$ & 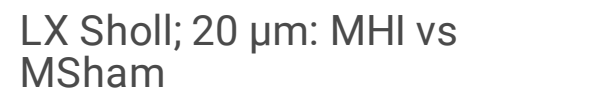 & $\begin{array}{l}\mathrm{t}(92)= \\
2.4\end{array}$ & 0.018 & 0.22 \\
\hline $2 b$ & $\begin{array}{l}\text { unpaired t- } \\
\text { test }\end{array}$ & $\begin{array}{l}\text { LX Sholl; } 30 \mu \mathrm{m}: \text { MHI vs } \\
\text { MSham }\end{array}$ & $\begin{array}{l}t(92)= \\
3.3\end{array}$ & 0.001 & 0.26 \\
\hline $2 b$ & $\begin{array}{l}\text { unpaired } t- \\
\text { test }\end{array}$ & $\begin{array}{l}\text { LX Sholl; } 40 \text { нm: MHI vs } \\
\text { MSham }\end{array}$ & $\begin{array}{l}t(92)= \\
4.2\end{array}$ & $<0.001$ & 0.3 \\
\hline $2 b$ & $\begin{array}{l}\text { unpaired t- } \\
\text { test }\end{array}$ & $\begin{array}{l}\text { LX Sholl; } 50 \text { нm: MHI vs } \\
\text { MSham }\end{array}$ & $\begin{array}{l}\mathrm{t}(92)= \\
3.7\end{array}$ & $<0.001$ & 0.28 \\
\hline $2 b$ & $\begin{array}{l}\text { unpaired t- } \\
\text { test }\end{array}$ & $\begin{array}{l}\text { LX Sholl; } 90 \mu \mathrm{m}: \text { MHI vs } \\
\text { MSham }\end{array}$ & $\begin{array}{l}t(92)= \\
2.2\end{array}$ & 0.027 & 0.21 \\
\hline $2 b$ & $\begin{array}{l}\text { unpaired t- } \\
\text { test }\end{array}$ & $\begin{array}{l}\text { LX Sholl; } 100 \mu \mathrm{m}: \text { MHI vs } \\
\text { MSham }\end{array}$ & $\begin{array}{l}t(92)= \\
3.4\end{array}$ & $<0.001$ & 0.27 \\
\hline $2 b$ & $\begin{array}{l}\text { unpaired t- } \\
\text { test }\end{array}$ & $\begin{array}{l}\text { LX Sholl; } 110 \mu \mathrm{m} \text { : MHI vs } \\
\text { MSham }\end{array}$ & $\begin{array}{l}t(92)= \\
2.5\end{array}$ & 0.014 & 0.23 \\
\hline $2 b$ & $\begin{array}{l}\text { unpaired t- } \\
\text { test }\end{array}$ & $\begin{array}{l}\text { LX Sholl; } 120 \mu \mathrm{m}: \text { MHI vs } \\
\text { MSham }\end{array}$ & $\begin{array}{l}\mathrm{t}(92)= \\
2.2\end{array}$ & 0.027 & 0.21 \\
\hline $2 b$ & $\begin{array}{l}\text { unpaired t- } \\
\text { test }\end{array}$ & LX Sholl; $20 \mu \mathrm{m}$ : FHI vs FSham & $\begin{array}{l}t(92)= \\
2.3\end{array}$ & 0.024 & 0.22 \\
\hline $2 b$ & $\begin{array}{l}\text { unpaired t- } \\
\text { test }\end{array}$ & LX Sholl; $30 \mu \mathrm{m}$ : FHI vs FSham & $\begin{array}{l}t(92)= \\
2.9\end{array}$ & 0.004 & 0.25 \\
\hline $2 b$ & $\begin{array}{l}\text { unpaired t- } \\
\text { test }\end{array}$ & LX Sholl; $50 \mu \mathrm{m}$ : FHI vs FSham & $\begin{array}{l}\mathrm{t}(92)= \\
2.9\end{array}$ & 0.005 & 0.25 \\
\hline $2 b$ & $\begin{array}{l}\text { unpaired t- } \\
\text { test }\end{array}$ & LX Sholl; $60 \mu \mathrm{m}$ : FHI vs FSham & $\begin{array}{l}t(92)= \\
3.8\end{array}$ & $<0.001$ & 0.28 \\
\hline $2 b$ & $\begin{array}{l}\text { unpaired t- } \\
\text { test }\end{array}$ & LX Sholl; $70 \mu \mathrm{m}$ : FHI vs FSham & $\begin{array}{l}t(92)= \\
2.4\end{array}$ & 0.02 & 0.22 \\
\hline $2 d$ & $\begin{array}{l}\text { unpaired t- } \\
\text { test }\end{array}$ & $\begin{array}{l}\text { LX Sholl; } 90 \mu \mathrm{m} \text { : FSham vs } \\
\text { MSham }\end{array}$ & $\begin{array}{l}t(92)= \\
2.5\end{array}$ & 0.013 & 0.23 \\
\hline $2 d$ & $\begin{array}{l}\text { unpaired t- } \\
\text { test }\end{array}$ & $\begin{array}{l}\text { LX Sholl; } 100 \text { um: FSham vs } \\
\text { MSham }\end{array}$ & $\begin{array}{l}\mathrm{t}(92)= \\
2.2\end{array}$ & 0.031 & 0.21 \\
\hline $2 d$ & $\begin{array}{l}\text { unpaired t- } \\
\text { test }\end{array}$ & LX Sholl; $40 \mu \mathrm{m}$ : FHI vs MHI & $\begin{array}{l}\mathrm{t}(92)= \\
2.2\end{array}$ & 0.027 & 0.21 \\
\hline
\end{tabular}




\begin{tabular}{|c|c|c|c|c|c|}
\hline \multirow{2}{*}{$\begin{array}{l}\text { Fig. } \\
\text { Panel }\end{array}$} & \multirow{2}{*}{$\begin{array}{l}\text { Statistical } \\
\text { Test }\end{array}$} & \multirow[t]{2}{*}{ Conditions } & \multicolumn{3}{|l|}{ Results } \\
\hline & & & $\begin{array}{l}\text { test } \\
\text { value }\end{array}$ & $\underset{\text { value }}{p-}$ & $\begin{array}{l}\text { 95\% Cl/Effect } \\
\text { size }\end{array}$ \\
\hline $2 d$ & $\begin{array}{l}\text { unpaired t- } \\
\text { test }\end{array}$ & LX Sholl; $110 \mu \mathrm{m}$ : FHI vs MHI & $\begin{array}{l}t(92)= \\
2.2\end{array}$ & 0.031 & 0.21 \\
\hline $2 d$ & $\begin{array}{l}\text { unpaired t- } \\
\text { test }\end{array}$ & LX Sholl; 120 m: FHI vs MHI & $\begin{array}{l}\mathrm{t}(92)= \\
2.2\end{array}$ & 0.017 & 0.21 \\
\hline
\end{tabular}

No effects of $\mathrm{HI}$ or sex were observed for average dendrite area, total dendrite area, average dendrite length, total dendrite length, or the number of dendritic segments (Fig. 2d-h).

\section{NanoString}

Using a custom designed NanoString array, we examined the impact of perinatal $\mathrm{HI}$ on gene expression associated with inflammation, phagocytosis, steroids/autacoids, masculinization/feminization, neurogenesis/synaptogenesis, neurotransmitters, cell markers, and genomic imprinting in the cerebellar vermis at PN17. HI males and females were compared to same-sex Sham animals to assess HI-related transcriptional changes in the cerebellar vermis (See Supplementary Fig. 2 online). Only three genes exhibited sex-specific expression. Integrin beta-5 (Itgb5) was upregulated in males $(p=0.028, \log 2 \mathrm{FC}=$ $0.075)$, along with expression of Brain derived neurotrophic factor ( $B d n f, p=0.043$, Log2FC $=0.119)$. Signal-regulatory protein alpha (Sirpa) expression was more abundant in females compared to males $(p=$ 0.045 , Log2FC $=-0.147)$.

The impact of $\mathrm{HI}$ on gene expression was markedly different for males and females. We found $\mathrm{HI}$ upregulated expression of mast cell marker Chymase $1(\mathrm{Cma} 1)$ in males $(p=0.036$, Log2FC $=0.795)$ and upregulated expression of microglia marker allograft inflammatory factor 1 (Aif1) in females $(p=0.05$ and Log2FC = 0.194; Fig. 3e). Inflammation-associated LDL receptor-related protein $1(L r p 1 ; p=0.015$ and Log2FC $=0.239)$ and CD40 molecule $(C d 40 ; p=0.029$ and Log2FC $=0.239)$ were significantly upregulated by $\mathrm{HI}$ in females, as was inflammatory mediator Interleukin $10(/ / 10)$ in males $(p=0.009$, Log2FC $=1.37$; Fig. 3a). We found a few genes associated with steroids or autacoids were increased by $\mathrm{HI}$ in females but showed no changes in males (Fig. 3b). This included genes involved in endocannabinoid signaling ( Faah, $p=0.03$ and Log2FC $=0.253 ;$ Cyp19a1, $p=0.045$ and Log2FC $=1.23$; Cnr1, $p=0.048$ and Log2FC $=0.159)$ and prostaglandin receptor signaling (Ptger1; $p=0.039$ and Log2FC $=0.96)$. In females, glutamine-catalyst Glutaminase $(G / s)$ expression was upregulated by $\mathrm{HI}(p=0.017$, Log2FC $=0.118$; Fig. $3 f)$. $\mathrm{HI}$ increased the expression of apoptotic regulator $\mathrm{BH} 3$ interacting domain death agonist $($ Bid $)$ in both males $(p=0.008$, Log2FC $=0.187)$ and females $(p=0.024$, Log 2FC $=0.132 ;$ Fig. $3 d)$. Lastly, $\mathrm{HI}$ altered the expression of genes related to the phagocytic activity of microglia (Fig. $3 \mathrm{c}$ ). In males, expression of $\mathrm{CD} 68(C d 68, p=0.005$, Log2FC $=0.338$ ) and Myeloid differentiation primary response protein (Myd88, $p=0.014$, Log2FC $=0.303$ ) was upregulated while expression of Signal-regulatory protein alpha (Sirpa, $p=0.031$, Log2FC $=-0.092)$ and Tyrosine kinase $3($ Tyro3, $p=0.041$, Log2FC $=$ 
$-0.106)$ was downregulated. By contrast $\mathrm{HI}$ increased expression of Sirpa $(p=0.009$, Log2FC $=0.234)$, in females, as well as for Complement C3b/C4b receptor 1 like $(C r 11, p=0.016$, Log2FC $=0.158)$ and Fractalkine receptor $(C \times 3 c r 1, p=0.03$, Log2FC $=0.231)$.

\section{Western blot and immunohistochemistry}

Western blot and immunohistochemistry were used to assess cerebellar protein expression 7 days after injury (Fig. 4b). Using western blot, we first investigated the effect of perinatal $\mathrm{HI}$ on protein markers for the predominant cell types and neurotransmitter in the cerebellum. Because there is well-known variability in protein expression signatures across the cortex of the cerebellar vermis, analysis was performed on samples composed of the anterior (lobules I-V) and central (lobules VIb-VII) transverse zones to detect regional effects of $\mathrm{HI}$ (Fig. 4a). In the anterior vermis of males and females (Table 3), HI reduced GAD65 and GAD 67 (main effect of treatment: $p=0.008$ and $p=0.0007$, respectively), and this decrease was greater in males as revealed by a significant main effect of $\operatorname{sex}(p=0.017$ and $p=0.021$, respectively; Fig. $4 c$ and 4 e). Additionally, there were no significant effects of HI on GAD 65 or 67 expression in the central vermis (Fig, $4 d$ and $4 f$ ). There were no significant effects of $H I$ or sex on levels of Purkinje neuronspecific calbindin (CALB), microglial- and macrophage-specific ionized calcium-binding adaptor molecule 1 (IBA1), or astrocyte- and Bergmann glia-specific glial fibrillary acidic protein (GFAP) in the anterior or central zones of the cerebellar vermis (See Supplementary Figure 3 online).

Table 3

Western blot (WB) analysis of glutamic acid decarboxylase (GAD) 65 and GAD67 (relative optical density) in the anterior zone (AZ) of the vermis of Sham and $\mathrm{HI}$ rats.

\begin{tabular}{|c|c|c|c|c|c|}
\hline \multirow{2}{*}{$\begin{array}{l}\text { Fig. } \\
\text { Panel }\end{array}$} & \multirow{2}{*}{$\begin{array}{l}\text { Statistical } \\
\text { Test }\end{array}$} & \multirow[t]{2}{*}{ Conditions } & \multicolumn{3}{|l|}{ Results } \\
\hline & & & test value & $\begin{array}{l}p- \\
\text { value }\end{array}$ & $\begin{array}{l}\text { 95\% Cl/Effect } \\
\text { size }\end{array}$ \\
\hline $4 c$ & $\begin{array}{l}\text { 2-way } \\
\text { ANOVA }\end{array}$ & AZ WB; GAD 65; main effect: sex & $\begin{array}{l}F(1,30)= \\
6.4\end{array}$ & 0.017 & {$[-0.53,-0.06]$} \\
\hline $4 c$ & $\begin{array}{l}\text { 2-way } \\
\text { ANOVA }\end{array}$ & $\begin{array}{l}\text { AZ WB; GAD 65; main effect: } \\
\text { treatment }\end{array}$ & $\begin{array}{l}F(1,30)= \\
8.0\end{array}$ & 0.008 & {$[0.09,0.56]$} \\
\hline $4 c$ & $\begin{array}{l}\text { unpaired t- } \\
\text { test }\end{array}$ & AZ WB; GAD 65: HI vs Sham & $t(32)=2.4$ & 0.021 & {$[-0.52,-0.05]$} \\
\hline $4 e$ & $\begin{array}{l}\text { 2-way } \\
\text { ANOVA }\end{array}$ & AZ WB; GAD 67; main effect: sex & $\begin{array}{l}F(1,30)= \\
14\end{array}$ & $<0.001$ & {$[-0.55,-0.16]$} \\
\hline $4 \mathrm{e}$ & $\begin{array}{l}\text { 2-way } \\
\text { ANOVA }\end{array}$ & $\begin{array}{l}\text { AZ WB; GAD 67; main effect: } \\
\text { treatment }\end{array}$ & $\begin{array}{l}F(1,30)= \\
5.9\end{array}$ & 0.021 & [0.04 to 0.42$]$ \\
\hline $4 e$ & $\begin{array}{l}\text { unpaired t- } \\
\text { test }\end{array}$ & AZ WB; GAD 67: HI vs Sham & $t(32)=1.9$ & 0.069 & {$[-0.41,0.016]$} \\
\hline
\end{tabular}


For enhanced spatial resolution, immunohistochemistry was used to analyze the influence of perinatal HI on Purkinje neuron number using CALB immunoreactivity at PN17 (Fig. 5). The density of CALB immunopositive Purkinje neurons (Table 4) was greater in males than females in the central (main effect of $\operatorname{sex} p=0.007$ ) and nodular (main effect of $\operatorname{sex} p=0.045$ ) vermis, but this was not influenced by $\mathrm{HI}$ (Fig. $5 f$ and $5 h$ ). Neither treatment nor sex influenced Purkinje neuron number in the anterior, central, or nodular vermis (Fig. 5c, 5e, and 5f). There were also no effects of sex or treatment on the density of CALB immunopositive Purkinje neurons in the anterior vermis (Fig. 5d).

Table 4

Immunohistochemical analysis of the number of Calbindin immunoreactive soma $\left(\mathrm{CALB}^{+} / \mathrm{mm}^{2}\right.$ ) and Calbindin optical density (OD; arbitrary units) in cerebellar vermal lobules Vla (LVla).

\begin{tabular}{|llllll|}
\hline $\begin{array}{l}\text { Fig. } \\
\text { Panel }\end{array}$ & Statistical & Conditions & Results & & \\
\cline { 4 - 6 } & Test & & test value & $\begin{array}{c}\text { p- } \\
\text { value }\end{array}$ & $\begin{array}{l}\text { 95\% Cl/Effect } \\
\text { size }\end{array}$ \\
\hline $5 e$ & $\begin{array}{l}\text { unpaired t- } \\
\text { test }\end{array}$ & $\begin{array}{l}\text { CALB+ soma/mm2: HI vs } \\
\text { Sham }\end{array}$ & $\mathrm{t}(23)=1.9$ & 0.075 & {$[-2.3,44]$} \\
\hline $5 f$ & $\begin{array}{l}\text { 2-way } \\
\text { ANOVA }\end{array}$ & CALB OD; main effect: sex & $\begin{array}{l}\mathrm{F}(1,21)= \\
9.0\end{array}$ & 0.007 & {$[0.028,0.15]$} \\
\hline $5 h$ & 2-way & CALB OD; main effect: sex & $\begin{array}{l}\mathrm{F}(1,20)= \\
4.5\end{array}$ & 0.046 & {$[0.0013,0.12]$} \\
\hline
\end{tabular}

There was no effect of $\mathrm{HI}$ on the total number of microglia, the number of phagocytic microglia, or the number of phagocytic cups in the anterior, central, or nodular vermis, as determined by immunohistochemistry for IBA1 (Fig. 6 and Fig. 7).

Expression of GFAP was quantified to investigate the effect of $\mathrm{HI}$ on astrocyte number and activity (Fig. 8). There were no main effects of sex, $\mathrm{Hl}$, or an interaction between the two on astrocyte number or density in the anterior, central, and nodular vermis.

Lastly, we measured the granular level (GL) area in vermal lobules I, Vla, and X in PN17 rats (Fig. 9). No sex differences or effects of $\mathrm{HI}$ were found.

\section{Discussion}

Until recently, the cerebellum and its vulnerability to perinatal $\mathrm{HI}$ have been underappreciated and unexplored. This neglect, in part, was due to the long-held belief the cerebellum functioned only in motor coordination and did not make important contributions to non-motor, cognitive and emotional domains. Using a model of term $\mathrm{HI}$ in the rat, we report a diffuse injury to the cerebellum seven days post-injury, with a focused impact on Purkinje neurons that differs in males versus females. When compared to the same-sex control group, male Purkinje neurons had fewer dendrites after $\mathrm{HI}$ while female Purkinje 
neurons tended to have more. To understand the origins of these Purkinje neuron alterations, we explored a targeted list of genes associated with inflammation, steroid hormones, autacoids, neurogenesis, synaptogenesis, and phagocytosis. We found a small number of genes altered in response to $\mathrm{Hl}$, with very little overlap between males and females. Western blot quantification of proteins to survey gross abnormalities in different cerebellar cell types and their neurotransmitters revealed decreased glutamic acid decarboxylase (GAD) expression, suggesting that a loss of inhibitory regulation may be the source of damage to Purkinje neurons. Immunohistochemistry and volumetric analyses found no evidence of gross changes to microglia, astrocytes, granular neurons, or the number of Purkinje neurons.

Findings from a line of research, initiated a decade ago, determined a latent sensitive period in cerebellar development during the second postnatal week in the rat ${ }^{23-25}$. This sensitive period in rats is analogous to full-term birth in humans, a time when males experience greater vulnerability to $\mathrm{HI}$ than females ${ }^{4-7,26}$. During this time endogenous prostaglandin E2 (PGE2), a lipid best known to mediate inflammation, is elevated in both sexes ${ }^{23,25}$. If PGE2 levels are thrown out of balance (i.e., increased or decreased) by inflammation or injury, the growth of Purkinje dendritic trees is altered, and later social cognitive and social behaviors are impaired in males only ${ }^{24,25}$. Interestingly, mRNA analysis, while not comprehensive, found evidence for facilitation of the prostaglandin synthesis pathway after $\mathrm{HI}$ in females. Expression of fatty acid amide hydrolase (Faah), which is the enzyme that produces the most important precursor in prostaglandin synthesis, and prostaglandin receptor subtype EP1 (Ptger1) were upregulated after $\mathrm{HI}$ in females only. This is intriguing given that PGE2 stunts the development of Purkinje neuron dendritic tree arborization, and EP1 activation is generally considered a source of neuronal damage following $\mathrm{HI}$ in cortical brain regions ${ }^{25,27}$. We did not measure either PGE2 or EP1 protein in this study, but this finding nevertheless highlights the central role of prostaglandin signaling in cerebellar development.

In the term infant, $\mathrm{HI}$ is typically associated with diffuse tissue loss, or hypoplasia, and damage to deep gray matter regions including the basal ganglia and thalamus ${ }^{28}$. Until very recently, perinatal $\mathrm{HI}$ was mainly characterized as a cerebral injury in the clinical setting. Nevertheless, the injury most often identified by MRI in the cerebellum of term infants experiencing $\mathrm{HI}$ is a bilateral, symmetrical decrease in hemisphere volume ${ }^{29}$. Though effects of perinatal $\mathrm{HI}$ on the cerebellum have been observed in experimental models, results are difficult to interpret due to inconsistencies in the timing of injury. The Rice-Vannucci method (i.e., permanent unilateral carotid ligation + period of systemic hypoxia) is by far the most widely used animal model to replicate HI. Initially developed in adult rats, the model has since been adapted for use in perinatal rodents, with PN7 pups being the current standard. Studies inducing HI in PN7 pups, which is best suited as a model of preterm neonatal injury, report reductions in the number of Purkinje neurons in both the right and left cerebellar hemispheres and abnormalities in Purkinje and granule cell dendrites ${ }^{30}$. It is currently considered that the PN10 Rice-Vannucci method, used here, is a more appropriate model for human infants at term ${ }^{31}$. To determine the effects of term-equivalent $\mathrm{HI}$ on Purkinje neuron morphological characteristics we used an AAV to sparsely label individual Purkinje neurons throughout the cerebellar vermis. Purkinje cell dendritic morphology was reconstructed in 3D and revealed that $\mathrm{HI}$ in the neonatal rat disrupts the dendritic branching of Purkinje neurons in the cerebellar 
vermis. Moreover, we find that the effect of $\mathrm{HI}$ on Purkinje neurons differs between the sexes, with males displaying a reduction in dendritic arborization and females displaying modest but significant dendritic outgrowth. These differences suggest either that repair mechanisms are initiated earlier in females or that females are protected from HI. Thus, optimal windows for intervention might differ between the sexes. Considering the timing of $\mathrm{HI}$ injury, our results in the cerebellum are consistent with those reported in studies modeling preterm neonatal $\mathrm{HI}$ injury. Cerebellar development is delayed relative to the rest of the central nervous system and undergoes significant cytoarchitectural changes after birth ${ }^{19,21}$. The second postnatal week in the rat cerebellum, which corresponds to birth in the human, is the most dynamic period of Purkinje neuron dendritic remodeling and a developmental window sensitive to extrinsic factors 32. During this period, the Purkinje neuron dendritic tree is rapidly expanding and organizing. The Purkinje neuron dendrites, which develop from multiple perisomatic processes, are pruned, leaving only a single primary dendrite that is innervated by a single climbing fiber. Simultaneously, Purkinje dendrites undergo tremendous growth and are remodeled from a multiplanar to monoplanar arrangement ${ }^{21}$.

The source of the increased vulnerability of males to deleterious consequences of $\mathrm{HI}$ on Purkinje neuron development is unknown. Purkinje neurons, the principal cells of the cerebellum and the only efferent of the cerebellar cortex, undergo tremendous growth during the perinatal period, a time when developing males experience elevated androgens ${ }^{33,34}$. Purkinje neuron dendritic branching and elongation extends into postnatal life, terminating with the completion of granule neuron migration and parallel fiber maturation (second to third postnatal week in the rodent and up to two years in the human) ${ }^{21}$. Earlier animal studies have shown that among the cell types of the cerebellum, Purkinje neurons are especially vulnerable to hypoxic insults, which is most likely a result of their high metabolic rate and associated oxygen demand ${ }^{35,36}$.

The calcium-binding protein Calbindin D28k is expressed by many types of neurons throughout the brain but is disproportionately abundant in Purkinje neurons, along with discrete populations of interneurons in the cerebral cortex and hippocampus, and so it is predominately used as a marker to identify these cell types ${ }^{37}$. Calbindin serves a threefold function as a Ca2+ buffer, transporter, and sensor ${ }^{38}$. While the precise function and regional specificity of Calbindin in Purkinje neurons are not fully elucidated, high expression is likely due to unique electrophysiological properties of Purkinje neurons, such as their high firing rate under resting conditions and characteristic complex spikes ${ }^{35,39}$. Androgens developmentally regulate calbindin as well as several calcium binding proteins and cation transporters, which can increase vulnerability to excitotoxic cell death ${ }^{40-42}$. We observed increased levels of calbindin in male Purkinje neurons, with and without $\mathrm{HI}$, suggesting this may be a source of increased sensitivity to altered excitability, thereby increasing male vulnerability.

Cumulative evidence supports a link between abnormal cerebellar development and major neurodevelopmental disorders that present with a strong gender bias, including autism spectrum disorders (ASDs), attention deficit hyperactivity disorder, and developmental dyslexia ${ }^{43,44}$. For example, perinatal cerebellum injury is the leading risk for ASDs, which are diagnosed more frequently in males 
than females. The two most consistent cerebellar abnormalities found in people with ASDs are Purkinje neuron loss (determined by postmortem histology) and reduced cerebellar volume (determined by MRI) 45 . The latter is believed to result from reductions in Purkinje neuron number and size ${ }^{46}$. Although developmental damage to the cerebellum, particularly Purkinje neurons, is strongly associated with neurodevelopmental disorders, the underlying pathogenesis and resultant behavioral defects, remain poorly understood. Purkinje neurons are the central components of all cerebellar circuits, the first neurons to populate the cerebellar cortex, and based on their ability to regulate the development of both inhibitory and excitatory neurons, they are considered key modulators of cerebellum development 47,48 . Lurcher mutant mice, which are characterized by postnatal degeneration of cerebellar Purkinje neurons, display ataxia, deterioration of cognitive functions, increased activity, and increased repetitive behaviors ${ }^{49,50}$. In rats, disruption of Purkinje neuron development by inflammation during the second postnatal week leads to stunting of Purkinje neuron dendrites and impairs juvenile social behavior only in males ${ }^{25}$. Early damage to the cerebellum can have broad, enduring consequences on the developmental trajectory of the cerebellum and behavior, but further research is needed to understand this complex relationship.

It remains unclear what role microglia are playing in the progression of cerebellum injury following perinatal HI. Microglia are key contributors to neurodevelopment and mediate distinct neuroimmune responses in the healthy and injured brain. Although much of our knowledge derives from studies in the cerebrum, microglia function in neurodevelopment by promoting cell genesis, controlling cell numbers, synaptic pruning, and apoptosis ${ }^{51-54}$. In the developing cerebellum, microglia promote apoptosis of immature Purkinje neurons and subsequently clear debris by phagocytosis ${ }^{55}$. In perinatal brain injury, one of the major pathogenic factors is microglia-mediated neuroinflammation, and most studies associate microglia activation detected at initial stages of injury with exacerbation of brain injury ${ }^{56-59}$. Using immunohistochemical methods we detected no changes in microglia numbers or morphology in the cerebellum one week after $\mathrm{HI}$, which is likely a result of the time between injury and assessment. Interestingly, our gene expression results hint at a role for microglia in the progression of cerebellar injury after $\mathrm{HI}$, given that several genes associated with microglia activation were increased in males after $\mathrm{HI}$, whereas in females there was an increase in Sirpa, a complement protein known to prevent phagocytosis of stressed cells ${ }^{60}$.

There are limitations to the current study. First is the intrinsic variability of the widely used Rice-Vannucci model of term HI. Procedural times and duration of isoflurane exposure, which we standardized and kept to a minimum, are believed to cause inconsistencies in brain injury ${ }^{61,62}$. Second, we did not investigate the behavioral outcomes of perinatal $\mathrm{HI}$ injury in adult rodents. Although this model gives rise to welldocumented behavioral phenotypes, including impaired spatial learning and memory, impaired motor control, and cognitive and sensory processing deficits, it would be impossible to ascertain what components of these behaviors rely on the cerebellum as opposed to the more frankly damaged cerebral cortex and hippocampus. These limitations highlight the need for a focal, term-equivalent $\mathrm{HI}$ model targeting the cerebellum. 
Collectively, the present studies add to a growing body of literature demonstrating that $\mathrm{HI}$ insult causes diffuse, bilateral injury in the term-equivalent cerebellum and that Purkinje neurons are particularly susceptible. To our knowledge, this is the first report of $\mathrm{HI}$ effects on Purkinje neuron dendritic branching patterns. A remaining question is the mechanism underlying the effects of $\mathrm{HI}$ on Purkinje neuron arborization. The timing of injury coincides with the sensitive period for dendritic remodeling of Purkinje cells, which is modulated by excitatory afferent fibers, trophic factors, and hormones. We also report a reduction in GAD signaling in the cerebellar cortex following $\mathrm{HI}$. This, along with the spatio-temporal location of injury, suggests that synaptic inputs to Purkinje neurons may be a target of HI. Further research is clearly needed to explore this and better understand how sex modulates $\mathrm{HI}$ in the termequivalent cerebellum.

\section{Methods}

\section{Animal husbandry and hypoxia-ischemia procedure}

All procedures were approved by the Institutional Animal Care and Use Committee of the University of Maryland and all methods were performed in accordance with the relevant guidelines and regulations. We have also ensured that our methodological and data reporting adhere to ARRIVE (Animal Research: Reporting of In Vivo Experiments) guidelines as published by the National Centre for the Replacement Refinement and Reduction of Animals in Research (NC3Rs) to maximize reproducibility and utility for systematic review. Study animals were maintained in the University of Maryland School of Medicine Animal Care Facility animal care facility on a 12:12 h light/dark cycle with ad libitum food and water. Timed-pregnant female Sprague-Dawley rats were obtained from Charles River (Fredrick, MD) and checked daily to determine the day of birth, which was designated as PN1. Litters were culled to 12 pups, when necessary, with equal numbers of males and females when possible, and randomly assigned to experimental conditions on PN1. To model $\mathrm{HI}$ in the term-equivalent infant brain, PN10 pups were subjected to a well-established ${ }^{63,64}$, modified version of the Rice-Vannucci method ${ }^{65}$. Briefly, pups were placed in a supine position and $3.0 \%$ isoflurane was delivered via nose cone for $1 \mathrm{~min}$, until anesthesia. Isoflurane was then reduced to a maintenance level of $1.5 \%$ for the remainder of the surgery ( 4.5 min). The right internal carotid artery was isolated, ligated twice, and severed between the ligations. The pups were then placed in a large, open jar within a circulating water bath $\left(37^{\circ} \mathrm{C}\right)$ for $25 \mathrm{~min}$ to recover from anesthesia, as indicated by normal breathing and color. Pups were then returned to the dam for $1 \mathrm{~h}$ to permit feeding after which they were placed in temperature-controlled chambers and exposed to $8 \%$ $\mathrm{O}_{2}: 98 \% \mathrm{~N}_{2}$ for $60 \mathrm{~min}$ to induce hypoxia. Sham-operated control pups were anesthetized for the average surgery time, incised, and sutured, but did not undergo carotid artery ligation or exposure to hypoxia.

\section{Adeno-associated virus (AAV) injection and Purkinje neuron reconstruction}

To achieve sparse labeling of Purkinje neurons at a resolution sufficient to complete analytical reconstruction, we used a viral construct purchased from the UPenn Viral Core 
(AAV8.CB7.Cl.eGFP.WPRE.RBG). This adeno-associated virus serotype 8 (AAV8) vector utilizes the CB7 promoter, human cytomegalovirus (CMV) and chicken beta actin fusion promoter, to drive the expression of eGFP. For this experiment, pups were injected with the virus within $6 \mathrm{~h}$ of birth on PN1. Bilateral intracerebroventricular injections were performed under cryoanesthesia. A 30 gauge, $1 \mu$ l Hamilton syringe attached to a stereotaxic manipulator was placed $1.0 \mathrm{~mm}$ caudal to Bregma and $1.0 \mathrm{~mm}$ lateral to the midline, lowered $4.0 \mathrm{~mm}$ into the brain, and then backed out $1.0 \mathrm{~mm}$ before infusion of $1 \mu \mathrm{l}$ of virus $\left(\geq 1 \times 10^{6} \mathrm{vg} / \mu \mathrm{l}\right)$. The separation of pups from the dam was kept to a minimum, for a duration of approximately $1 \mathrm{~h}$. On PN10 pups were subjected to HI or Sham surgery as described above. On PN17, pups were deeply anesthetized with pentobarbital sodium, perfused with ice-cold phosphate-buffered saline (PBS, $0.1 \mathrm{M}, \mathrm{pH}=7.4$ ) followed by $4 \%$ paraformaldehyde (PFA; $\mathrm{pH}=7.0$ ). Brains were harvested, post-fixed in $4 \%$ PFA for $24 \mathrm{~h}$ at $4^{\circ} \mathrm{C}$, and then transferred to $0.1 \mathrm{M}$ phosphate buffer and stored at $4^{\circ} \mathrm{C}$ until use. Cerebella were dissected and divided into two halves at the midsagittal line, embedded in $4 \%$ agarose, and sectioned sagittally on a vibratome (Leica, VT1000S). Free-floating $150 \mu \mathrm{m}$ sections were collected in cryoprotectant, mounted onto silane-coated slides, and coverslipped with ProLong Diamond Antifade (Thermo Fisher Scientific).

Single-channel, confocal images of Purkinje neurons in cerebellar vermal lobules I, Vla, and X were captured on a spinning-disc microscope (Nikon CSU-W1) with a Plan Fluor 40x oil-immersion objective ( $1.3 \mathrm{NA}$ ) by using a $488 \mathrm{~nm}$ laser. Confocal serial sections with a frame size of $2044 \times 2048$ pixels were captured at intervals of $0.1 \mu \mathrm{m}$ in the z-dimension to acquire whole-cell images with a resolution of 0.16 $\mu \mathrm{m} / \mathrm{px}$. Images taken in Lobule I (LI) were retained for future analyses. Volume-rendered, 3D models of Purkinje neurons in lobules Vla (LVla) and X (LX) were reconstructed from raw z-stacks using Imaris software (version 9.0.2; Bitplane, Saint Paul, MN) in the Surpass view. The Filament Tracer AutoDepth tool was then used to generate 3D dendritic tree models for Purkinje neurons. Next, Imaris Filament Tracer was used to analyze morphological properties (number of dendrite segments, average dendrite length, total dendritic length, average dendrite area, total dendritic area) and Sholl analysis ${ }^{66}$. Sholl analysis quantified the number of dendritic processes intersecting with a series of concentric circles spaced at 10 $\mu \mathrm{m}$ intervals from the Purkinje soma. Three to five Purkinje cells per animal were quantified and the average values for each animal were calculated. Individual animals were treated as subjects for statistical analysis ( $n=4-6 /$ group/sex). Image acquisition and Purkinje neuron tracing via Imaris Filament Tracer were performed by investigators blinded to the treatment group and sex.

\section{Gene expression array (NanoString)}

Male and female rat pups were subjected to $\mathrm{HI}$ or Sham surgery on PN10 and euthanized with a lethal dose of sodium pentobarbital ( $650 \mathrm{mg} / \mathrm{kg}$, intraperitoneally) on PN17 ( $\mathrm{n}=6 / \mathrm{group} / \mathrm{sex}$ ). The cerebellum was divided along the midsagittal plane and the cerebellar vermis was separated from the hemispheres. For total RNA extraction, the right vermis was incubated in $500 \mu$ l of Qiazol (Qiagen \#79306) with $1 \mathrm{~mm}$ zirconia/silica beads (BioSpec \#111079110z) and homogenized at $4^{\circ} \mathrm{C}$ using a Bullet Blender for $5 \mathrm{~min}$ (speed $=6$ ) after which $500 \mu \mathrm{l}$ of Qiazol and $200 \mu \mathrm{l}$ of BAN (Molecular Research Center, Cat.\# BN191) were added to the samples and centrifuged at $12,000 \mathrm{~g}$ for $15 \mathrm{~min}$ at $4^{\circ} \mathrm{C}$ allowing phase separation to 
occur. The clear layer was removed and mixed with $475 \mu$ of molecular biology grade $70 \%$ ethanol and pipetted onto a RNeasy spin column and RNA isolation proceeded according to the manufacturer's protocol (Qiagen \#74106/74104). Isolated RNA was eluted in a $40 \mu$ l volume and tested using an Agilent 2100 Bioanalyzer to ensure it met specifications for purity (RNA integrity number $\geq 9$ ) and concentration $(\geq 12.5 \mathrm{ng} / \mu \mathrm{l})$.

Gene expression profiling of $\mathrm{HI}$ response was performed using a custom NanoString nCounter codeset (rat) that we designed to allow for the multiplexed assessment of 171 genes related to inflammation, phagocytosis, steroids/autacoids, masculinization/feminization, neurogenesis/synaptogenesis, neurotransmitters, cell markers, and imprinted genes. RNA was processed on the NanoString nCounter Analysis System by the University of Maryland Baltimore's Institute for Genome Sciences using NanoString's standard consumables and assay procedures ${ }^{67}$. NanoString Reporter Code Count (RCC) files were analyzed using nSolver analysis software (Version 4.0). All samples passed QC parameters.

\section{Western blot}

On PN10 male and female rat pups underwent Sham or HI surgery and were euthanized by sodium pentobarbital on PN17, as described above ( $n=4-6 /$ group/sex). The cerebellum was divided along the midsagittal plane and the cerebellar vermis was separated from the hemispheres. The left and right vermis was subdivided into five transverse domains in the anterior-posterior axis, which are identified by zebrin II expression ${ }^{68,69}:$ 1) the anterior zone (lobules I-V), 2) lobule Vla, 3) the central zone (lobules VIbVII), 4) the posterior zone (lobules XIII- dorsal IX), and 5) the nodular zone (lobules IX ventral - X). Tissue from each region was flash-frozen using 2-methyl butane submerged in dry ice and stored at $-80^{\circ} \mathrm{C}$ until processing. Tissue was homogenized in RIPA buffer with added phosphatase (1:1000, Sigma, Cat.\# P0044) and protease (1:1000, Sigma, Cat.\# P8340) inhibitors. After homogenization, samples were centrifuged at $3000 \mathrm{rpm}$ at $4^{\circ} \mathrm{C}$ for $10 \mathrm{~min}$. The protein supernatant was collected, and total protein concentration was determined by Bradford assay ${ }^{70}$ using an Infinite M1000 Pro (Tecan). Fifteen micrograms of protein per sample were electrophoresed in separate lanes on a Novex WedgeWell 10-20\% tris-glycine gel (Invitrogen Cat. \# XP10205BOX and transferred to a PVDF membrane (0.2 $\mu \mathrm{m}$, Bio-Rad Cat.\# 1704156). Membranes were blocked in Odyssey ${ }^{\circledR}$ blocking buffer (LI-COR, Cat.\# 927-50000) diluted 1:1 with Tris-buffered saline (TBS) for $1 \mathrm{~h}$ at room temperature and incubated with primary antibodies overnight ( $20-24 \mathrm{~h})$ at $4^{\circ} \mathrm{C}$ on a shaking platform. Subsequently, membranes were rinsed and incubated for $1 \mathrm{~h}$ with secondary antibodies. Primary antibodies and their dilutions were as follows: goat anti-beta actin (1:1000; Abcam, Cat.\# AB8229), mouse anti-calbindin D-28k (1:3000, Sigma, Cat.\# C9848), rabbit anti-GAPDH (1:20000, Sigma, Cat.\# G9545), rabbit anti-GFAP (1:15000, Abcam, Cat.\# AB7260), rabbit anti-glutamate decarboxylase 65/67 (1:800; Millipore, Cat.\# ABN904), and rabbit anti-IBA1 (1:1000, Wako, Cat.\# 016-20001). Secondary antibodies used were as follows: IRDye 680RD donkey anti-rabbit (1:20000, LI-COR, Cat.\# 926-68073), IRDye 800CW donkey anti-mouse (1:20000, LI-COR, Cat.\# 92632212), IRDye 680RD donkey anti-goat (1:20000, LI-COR, Cat.\# 925-68074), and IRDye 800CW goat antirabbit (1:20000, LI-COR, Cat.\# 926-32211). 
Membranes were imaged in both the 700 and $800 \mathrm{~nm}$ channels using an Odyssey CLx scanner (LI-COR) and quantified using ImageStudio software (LI-COR). The proteins of interest were detected as a band with a relative molecular weight of $67 \mathrm{kDa}$ for GAD67, $65 \mathrm{kDa}$ for GAD65, $50 \mathrm{kDa}$ for GFAP, $42 \mathrm{kDa}$ for $\beta$ ACTIN, $36 \mathrm{kDa}$ for GAPDH, $28 \mathrm{kDa}$ for Calbindin, and $17 \mathrm{kDa}$ for IBA1. The optical intensity for each protein of interest was normalized to GAPDH and $\beta$-ACTIN and the resulting values were averaged for each sample. Each sample was normalized to a standard internal control sample to allow for comparison across membranes. Relative protein quantification is expressed as "Normalized Optical Intensity."

\section{Immunohistochemistry (IHC), histology, and quantification}

Male and female rats were subjected to HI or Sham surgery on PN10, as described above. On PN17, rats were anesthetized with sodium pentobarbital and perfused with ice-cold PBS, followed by $4 \%$ PFA. Brains were harvested and post-fixed in $4 \%$ PFA for $24 \mathrm{~h}$ at $4^{\circ} \mathrm{C}$, transferred to $30 \%$ sucrose and stored at $4^{\circ} \mathrm{C}$ until use. The cerebellum was hemisected by a midline sagittal cut through the vermis. The left and right halves of the cerebellum were then subdivided into the vermis and hemisphere regions and cryosectioned sagittally into six series of $45 \mu \mathrm{m}$ sections. Free-floating sections were stored at $-20^{\circ} \mathrm{C}$ in cryoprotectant until use. Separate series were used for each $\mathrm{IHC}$ analysis. Primary antibodies used include the following: rabbit anti-GFAP $(0.16 \mu \mathrm{g} / \mathrm{ml}$, Abcam Cat\# ab7260, RRID: AB_305808); mouse anti-calbindin $(3-11 \mu \mathrm{g} / \mathrm{ml}$; Sigma Cat\# C9848, RRID: AB_476894); and rabbit anti-IBA1 (0.05-0.07 $\mu \mathrm{g} / \mathrm{ml}$, Wako Cat\# 019-19741; RRID: AB_839504). Secondary antibodies used include the following: biotinylated goat anti-rabbit (3 $\mu \mathrm{g} / \mathrm{ml}$, Vector Cat\#BA-1000, RRID: AB_2313606) and biotinylated horse anti-mouse $(3 \mu \mathrm{g} / \mathrm{ml}$, Vector Cat\#BA-2000; RRID: AB_2313581). All incubations were performed at room temperature unless stated otherwise. All analyses were carried out by investigators blinded to the treatment group and sex.

GFAP and Calbindin (CALB) IHC. Sections from the left and right vermis were mounted onto silane-coated slides and washed in TBS $(0.05 \mathrm{M}, \mathrm{pH}=7.6)$. To enhance immunolabeling of CALB, antigen retrieval $\left(0.01 \mathrm{M}\right.$ sodium citrate, $\mathrm{pH}=6.0$ for $20 \mathrm{~min}$ at $95^{\circ} \mathrm{C}$ ) was performed and slides were cooled to room temperature and incubated in a peroxide solution (50\% histology-grade methanol/ $0.3 \% \mathrm{H}_{2} \mathrm{O}_{2}$ in TBS) for 30 min. Antigen retrieval was not required for GFAP immunolabeling. Slides were blocked with $5 \%$ normal goat serum (NGS) in TBS containing $0.4 \%$ Triton X-100 (TBST) for $1 \mathrm{~h}$, followed by incubation in primary antibody solution containing $5 \%$ NGS in TBST overnight. The next day, slides were incubated with secondary antibody solution (2.5\% NGS in TBST) for $1 \mathrm{~h}$, incubated in $A B C$ reagent (1:500 dilution; Vectastain Elite ABC Kit, Vector Laboratories) in TBST for $1 \mathrm{~h}$, and visualized using DAB chromagen (0.05\% 3,3'-diaminobenzidine, $0.006 \%$ hydrogen peroxide; Sigma-Aldrich D-5905). The DAB reaction was allowed to proceed until completion ( 3-5 $\mathrm{min}$ ). Sections on slides were dehydrated in a series of ascending ethanol, defatted in $100 \%$ xylene, and coverslipped with DPX mounting medium (VWR International Inc).

Brightfield images of cerebellar vermal lobules I, Vla and X were captured on a Keyence BZ-X700 microscope using a 20x (0.75 NA) objective and BZ-X Viewer software and were subsequently quantified using Image J software. The total number of $\mathrm{GFAP}^{+}$cells in the granule and Purkinje layers (GL and PL, 
respectively) were counted and this number was divided by the combined area of the GL and PL to obtain the density of $\mathrm{GFAP}^{+}$cells. Similarly, the number of $\mathrm{CALB}^{+}$soma within the PL was counted and normalized to the combined area of the PL and molecular layer $(M L)$ to obtain the density of CALB ${ }^{+}$cells. In addition, CALB and GFAP relative amounts were analyzed by measuring the integrated optical density (OD) as described in ${ }^{71,72}$. In brief, brightfield images were converted to grayscale, and the Image $J$ Optical Density calibration tool was used to determine the intensity of CALB immunostaining in the PL and GFAP immunostaining in the GL and PL. For each image, the background OD was measured and subtracted from the absolute OD values. Relative ODs were calculated by dividing the optical density by the measured tissue area. All GFAP and CALB measurements were performed in lobules I, Vla, and X of the left and right cerebellar vermis. A total of 3 sections per animal were analyzed and the values were averaged. Individual animals were treated as subjects for statistical analysis ( $n=3-7 / \mathrm{group} / \mathrm{sex}$ ).

IBA1 IHC: Free-floating cerebellar sections were rinsed with 0.1M PBS, incubated with $0.3 \%$ hydrogen peroxide in PBS for $30 \mathrm{~min}$, and rinsed again. Sections were incubated in a primary antibody solution containing $10 \%$ of bovine serum albumin (BSA) in PBS with $0.4 \%$ Triton X-100 (PBST) for 30 min with constant agitation and then kept for $24 \mathrm{~h}$ at $4^{\circ} \mathrm{C}$ with constant agitation. Sections were then incubated with biotinylated anti-rabbit secondary antibody in PBST for $1 \mathrm{~h}$, incubated in ABC reagent in PBST for 1 $\mathrm{h}$, and visualized using nickel-enhanced DAB chromogen (0.05\% 3,3'-diaminobenzidine, $0.2 \%$ nickel (II) sulfate, and 0.006\% hydrogen peroxide; Sigma-Aldrich) until the reaction was complete ( 8-10 $\mathrm{min})$. Finally, sections were exhaustively rinsed in PBS, mounted on silane-coated slides, dehydrated with ascending alcohol concentrations, defatted with xylene, and coverslipped with DPX mounting medium.

A design-based unbiased stereological method was performed to quantify microglia and phagocytic cups across the cerebellar vermis. We used Stereolnvestigator 10 software (Microbrightfield) interfaced with an Olympus BX51 microscope and an MBF Bioscience 01-MBF-2000R-F-CLR-12 Digital Camera (Color 12 $\mathrm{BIT}$ ). Counts were performed in lobules I, Vla, and $\mathrm{X}$ of the right vermis. The optical fractionator probe method was used to estimate cell and phagocytic cup densities. Both Iba $1^{+}$cells and phagocytic cups were counted at 20X magnification. The overall estimated volume of each counting region sampled in the vermis was used to normalize estimated counts to obtain an estimation of the average density of objects of interest (e.g., microglia, phagocytic cups), which was expressed as an estimated number/ $\mu \mathrm{m}^{3}$ (relative density measurement). A total of three cerebellar sections per animal were used with a physical distance of $225 \mu \mathrm{m}$ between them to avoid any cell being counted twice during stereological analysis. Individual animals were treated as subjects for statistical analysis ( $n=3-5 /$ group/sex).

Granule layer area analysis: Sections were counterstained with either hematoxylin or methyl green, dehydrated in an ascending ethanol series, defatted in xylene, and coverslipped with DPX mounting medium. The area occupied by cerebellar granule cells was evaluated following methyl green pyronin staining. Sections $(45 \mu \mathrm{m})$ from the PN17 vermis were quantified using the quick circle tool on Neurolucida 10 interfaced with an OLYMPUS BX51 microscope and an MBF Bioscience 01-MBF-2000R-FCLR-12 Digital Camera (Color 12 BIT). Analyses were performed in three regions of the cerebellar vermis 
(LI, LVla, and LX). Measurements were averaged from the left and right vermes of 3 sections and individual animals were treated as the subjects for statistical analyses. Experimental subjects were categorized into two groups: Sham and $\mathrm{HI}(\mathrm{n}=3-5 /$ group/sex).

\section{Statistical analysis}

Purkinje neuron morphology, western blot, and IHC data are expressed as the mean and SD and follow homogeneity of variance. For Sholl analysis, we first used a three-way repeated measures ANOVA with treatment, sex, and distance from soma as fixed factors. If a significant interaction was detected, a post hoc two-way unpaired student's $t$ test was used to compare the number of dendrites for each distance from the soma. For all other morphological measurements and western blot data, we conducted two-way ANOVAs with sex and treatment as fixed factors followed by post hoc pairwise comparisons. All statistical tests were computed in GraphPad Prism 7.

NanoString expression data was normalized to the geometric mean of: (1) positive and negative controls included in the NanoString Codeset to adjust for background thresholding and to normalize sample input and differences in hybridization, and (2) the geometric mean of ten reference genes (Alas1, Eef1g, G6pd, Gapdh, Oaz1, Polr2a, Ppia, Rp/19, Sdha, Tbp, and Dlk1) for codeset content normalization. The reference gene list was collated based on a literature review of housekeeping targets that yield best results for quantitative gene expression analysis studies and each reference gene showed minimal variation among the treatment groups. Significance was determined by a two-tailed t-test of the log-transformed normalized data within the nSolver Software Package and graphed using GraphPad Prism 7. Significance was denoted when $p \leq 0.05$.

\section{Declarations}

\section{Acknowledgments:}

We are grateful to Keti Bardhi, Jill Bumgardner, Joseph Mauban of the University of Maryland School of Medicine Center for Innovative Biomedical Resources confocal microscopy core, the Society for Neuroscience's Neuroscience Scholars Program, and the University of Washington BRAINS program.

\section{Author's contributions:}

S.E.A. and M.M.M. designed research; S.E.A, M.P.P., J.W., A.R.R.L., E.L.G. and A.M. performed research; S.E.A. and M.P.P. analyzed data; S.E.A., A.R.R.L., M.P.P. and M.M.M. wrote the manuscript.

\section{Additional Information:}

There are no competing interests, financial and/or non-financial, for any of the authors. This work was supported by the NIH Grant P01HD085928 and 5R01MH091424 to M.M.M.

\section{References}


1. Badawi, N. et al. Intrapartum risk factors for newborn encephalopathy: the Western Australian casecontrol study. BMJ 317, 1554-1558 (1998).

2. Zupan, J. \& Åhman, E. Neonatal and perinatal mortality: country, regional and global estimates. (World Health Organization, 2006).

3. Cowan, F. et al. Origin and timing of brain lesions in term infants with neonatal encephalopathy. The Lancet 361, 736-742 (2003).

4. Futrakul, S., Praisuwanna, P. \& Thaitumyanon, P. Risk factors for hypoxic-ischemic encephalopathy in asphyxiated newborn infants. J Med Assoc Thai 89, 322-328 (2006).

5. Wu, Y. W. et al. Nighttime delivery and risk of neonatal encephalopathy. American Journal of Obstetrics and Gynecology 204, 37.e1-37.e6 (2011).

6. Lauterbach, M. D., Raz, S. \& Sander, C. J. Neonatal hypoxic risk in preterm birth infants: the influence of sex and severity of respiratory distress on cognitive recovery. Neuropsychology 15, 411-420 (2001).

7. Smith, A. L., Alexander, M., Rosenkrantz, T. S., Sadek, M. L. \& Fitch, R. H. Sex differences in behavioral outcome following neonatal hypoxia ischemia: insights from a clinical meta-analysis and a rodent model of induced hypoxic ischemic brain injury. Exp. Neurol. 254, 54-67 (2014).

8. Charriaut-Marlangue, C., Besson, V. C. \& Baud, O. Sexually Dimorphic Outcomes after Neonatal Stroke and Hypoxia-Ischemia. Int J Mol Sci 19, (2017).

9. Netto, C. A., Sanches, E., Odorcyk, F. K., Duran-Carabali, L. E. \& Weis, S. N. Sex-dependent consequences of neonatal brain hypoxia-ischemia in the rat: Sex Differences With Neonatal Brain Hypoxia-Ischemia. Journal of Neuroscience Research 95, 409-421 (2017).

10. Rosenkrantz, T. S., Hussain, Z. \& Fitch, R. H. Sex Differences in Brain Injury and Repair in Newborn Infants: Clinical Evidence and Biological Mechanisms. Front. Pediatr. 7, 211 (2019).

11. Sheth, R. D., Bodensteiner, J. B., Riggs, J. E. \& Schochet, S. S. Differential Involvement of the Brain in Neonatal Asphyxia: A Pathogenic Explanation. J Child Neurol 10, 464-466 (1995).

12. Volpe, J. J. Neurology of the newborn. (Saunders/Elsevier, 2008).

13. Ferriero, D. M. Neonatal Brain Injury. N Engl J Med 351, 1985-1995 (2004).

14. Miller, S. P. et al. Serial quantitative diffusion tensor MRI of the premature brain: Development in newborns with and without injury. J. Magn. Reson. Imaging 16, 621-632 (2002).

15. Limperopoulos, C., Robertson, R. L., Sullivan, N. R., Bassan, H. \& du Plessis, A. J. Cerebellar Injury in Term Infants: Clinical Characteristics, Magnetic Resonance Imaging Findings, and Outcome. Pediatric Neurology 41, 1-8 (2009).

16. Kwan, S. et al. Injury to the Cerebellum in Term Asphyxiated Newborns Treated with Hypothermia. AJNR Am J Neuroradio/ 36, 1542-1549 (2015).

17. Salman, M. S. \& Tsai, P. The Role of the Pediatric Cerebellum in Motor Functions, Cognition, and Behavior: A Clinical Perspective. Neuroimaging Clin. N. Am. 26, 317-329 (2016). 
18. Ábrahám, H., Tornóczky, T., Kosztolányi, G. \& Seress, L. Cell formation in the cortical layers of the developing human cerebellum. Int. j. dev. neurosci. 19, 53-62 (2001).

19. Haraguchi, S. et al. Estradiol Promotes Purkinje Dendritic Growth, Spinogenesis, and Synaptogenesis During Neonatal Life by Inducing the Expression of BDNF. Cerebellum 11, 416-417 (2012).

20. Sarna, J. R. \& Hawkes, R. Patterned Purkinje cell death in the cerebellum. Progress in Neurobiology 70, 473-507 (2003).

21. Altman, J. Postnatal development of the cerebellar cortex in the rat. II. Phases in the maturation of Purkinje cells and of the molecular layer. J. Comp. Neurol. 145, 399-463 (1972).

22. Butts, T., Green, M. J. \& Wingate, R. J. T. Development of the cerebellum: simple steps to make a 'little brain'. Development 141, 4031-4041 (2014).

23. Dean, S. L., Knutson, J. F., Krebs-Kraft, D. L. \& McCarthy, M. M. Prostaglandin E2 is an endogenous modulator of cerebellar development and complex behavior during a sensitive postnatal period. Eur. J. Neurosci. 35, 1218-1229 (2012).

24. Dean, S. L. et al. Prostaglandin E2 stimulates estradiol synthesis in the cerebellum postnatally with associated effects on Purkinje neuron dendritic arbor and electrophysiological properties. Endocrinology 153, 5415-5427 (2012).

25. Hoffman, J. F., Wright, C. L. \& McCarthy, M. M. A Critical Period in Purkinje Cell Development Is Mediated by Local Estradiol Synthesis, Disrupted by Inflammation, and Has Enduring Consequences Only for Males. Journal of Neuroscience 36, 10039-10049 (2016).

26. Arambula, S. E., Reinl, E. L., El Demerdash, N., McCarthy, M. M. \& Robertson, C. L. Sex differences in pediatric traumatic brain injury. Experimental Neurology 317, 168-179 (2019).

27. Abe, T. et al. The neuroprotective effect of prostaglandin E2 EP1 receptor inhibition has a wide therapeutic window, is sustained in time and is not sexually dimorphic. J Cereb Blood Flow Metab 29, 66-72 (2009).

28. Yıldız, E. P., Ekici, B. \& Tatlı, B. Neonatal hypoxic ischemic encephalopathy: an update on disease pathogenesis and treatment. Expert Review of Neurotherapeutics 17, 449-459 (2017).

29. Kinney, H. C. \& Volpe, J. J. Hypoxic-Ischemic Injury in the Term Infant. in Volpe's Neurology of the Newborn 484-499 (Elsevier, 2018). doi:10.1016/B978-0-323-42876-7.00018-1.

30. Benitez, S. G., Castro, A. E., Patterson, S. I., Muñoz, E. M. \& Seltzer, A. M. Hypoxic Preconditioning Differentially Affects GABAergic and Glutamatergic Neuronal Cells in the Injured Cerebellum of the Neonatal Rat. PLOS ONE 9, e102056 (2014).

31. Patel, S. D., Pierce, L., Ciardiello, A. J. \& Vannucci, S. J. Neonatal encephalopathy: pre-clinical studies in neuroprotection. Biochemical Society Transactions 42, 564-568 (2014).

32. Dusart, I. \& Flamant, F. Profound morphological and functional changes of rodent Purkinje cells between the first and the second postnatal weeks: a metamorphosis? Front. Neuroanat. 6, (2012).

33. Martinez, S., Andreu, A., Mecklenburg, N. \& Echevarria, D. Cellular and molecular basis of cerebellar development. Front. Neuroanat. 7, (2013). 
34. Perez-Pouchoulen, M., Yu, S. J., Roby, C. R., Bonsavage, N. \& McCarthy, M. M. Regulatory Control of Microglial Phagocytosis by Estradiol and Prostaglandin E2 in the Developing Rat Cerebellum. Cerebellum 18, 882-895 (2019).

35. Katsetos, C. D. et al. Acute Hypoxia-Induced Alterations of Calbindin-D $28 \mathrm{k}$ Immunoreactivity in Cerebellar purkinje Cells of the Guinea pig Fetus at Term. J Neuropathol Exp Neuro/ 60, 470-482 (2001).

36. Welsh, J. P. et al. Why do Purkinje cells die so easily after global brain ischemia? Aldolase C, EAAT4, and the cerebellar contribution to posthypoxic myoclonus. Adv Neuro/ 89, 331-359 (2002).

37. Baimbridge, K. G., Celio, M. R. \& Rogers, J. H. Calcium-binding proteins in the nervous system. Trends in Neurosciences 15, 303-308 (1992).

38. Schmidt, H. Three functional facets of calbindin D-28k. Front. Mol. Neurosci. 5, (2012).

39. Schmidt, H., Schwaller, B. \& Eilers, J. Calbindin D28k targets myo-inositol monophosphatase in spines and dendrites of cerebellar Purkinje neurons. Proceedings of the National Academy of Sciences 102, 5850-5855 (2005).

40. Brager, D. H., Sickel, M. J. \& McCarthy, M. M. Developmental sex differences in calbindin-D(28K) and calretinin immunoreactivity in the neonatal rat hypothalamus. J Neurobiol 42, 315-322 (2000).

41. Sickel, M. J. \& McCarthy, M. M. Calbindin-D28k immunoreactivity is a marker for a subdivision of the sexually dimorphic nucleus of the preoptic area of the rat: developmental profile and gonadal steroid modulation. J Neuroendocrinol 12, 397-402 (2000).

42. Zup, S. L., Edwards, N. S. \& McCarthy, M. M. Sex- and age-dependent effects of androgens on glutamate-induced cell death and intracellular calcium regulation in the developing hippocampus. Neuroscience 281, 77-87 (2014).

43. Stoodley, C. J. The Cerebellum and Neurodevelopmental Disorders. Cerebellum 15, 34-37 (2016).

44. Wang, S. S.-H., Kloth, A. D. \& Badura, A. The Cerebellum, Sensitive Periods, and Autism. Neuron 83, 518-532 (2014).

45. Fatemi, S. H. et al. Consensus Paper: Pathological Role of the Cerebellum in Autism. Cerebellum 11, 777-807 (2012).

46. D’Mello, A. M. \& Stoodley, C. J. Cerebro-cerebellar circuits in autism spectrum disorder. Front. Neurosci. 9, (2015).

47. Dahmane, N. \& Ruiz-i-Altaba, A. Sonic hedgehog regulates the growth and patterning of the cerebellum. Development 126, 3089-3100 (1999).

48. van der Heijden, M. E. \& Sillitoe, R. V. Interactions Between Purkinje Cells and Granule Cells Coordinate the Development of Functional Cerebellar Circuits. Neuroscience 462, 4-21 (2021).

49. Lalonde, R., Lamarre, Y. \& Smith, A. M. Does the mutant mouse lurcher have deficits in spatially oriented behaviours? Brain Research 455, 24-30 (1988).

50. Lalonde, R., Botez, M. I., Joyal, C. C. \& Caumartin, M. Motor abnormalities in lurcher mutant mice. Physiology \& Behavior 51, 523-525 (1992). 
51. Arambula, S. E. \& McCarthy, M. M. Neuroendocrine-Immune Crosstalk Shapes Sex-Specific Brain Development. Endocrinology 161, bqaa055 (2020).

52. Lenz, K. M., Nugent, B. M., Haliyur, R. \& McCarthy, M. M. Microglia are essential to masculinization of brain and behavior. J. Neurosci. 33, 2761-2772 (2013).

53. Paolicelli, R. C. et al. Synaptic pruning by microglia is necessary for normal brain development. Science 333, 1456-1458 (2011).

54. Stoessel, M. B. \& Majewska, A. K. Little cells of the little brain: microglia in cerebellar development and function. Trends in Neurosciences 44, 564-578 (2021).

55. Marín-Teva, J. L. et al. Microglia promote the death of developing Purkinje cells. Neuron 41, 535-547 (2004).

56. Baud, O. \& Saint-Faust, M. Neuroinflammation in the Developing Brain: Risk Factors, Involvement of Microglial Cells, and Implication for Early Anesthesia. Anesthesia \& Analgesia 128, 718-725 (2019).

57. Bigio, M. R. D. \& Beckery, L. E. Microglial aggregation in the dentate gyrus: a marker of mild hypoxicischaemic brain insult in human infants. Neuropathol Appl Neurobio/ 20, 144-151 (1994).

58. McRae, A., Gilland, E., Bona, E. \& Hagberg, H. Microglia activation after neonatal hypoxic-ischemia. Developmental Brain Research 84, 245-252 (1995).

59. Verney, C. et al. Microglial Reaction in Axonal Crossroads Is a Hallmark of Noncystic Periventricular White Matter Injury in Very Preterm Infants. J Neuropathol Exp Neurol 71, 251-264 (2012).

60. Lehrman, E. K. et al. CD47 Protects Synapses from Excess Microglia-Mediated Pruning during Development. Neuron 100, 120-134.e6 (2018).

61. Chen, H. et al. Prolonged Exposure to Isoflurane Ameliorates Infarction Severity in the Rat Pup Model of Neonatal Hypoxia-Ischemia. Transl. Stroke Res. 2, 382-390 (2011).

62. Hamdy, N., Eide, S., Sun, H.-S. \& Feng, Z.-P. Animal models for neonatal brain injury induced by hypoxic ischemic conditions in rodents. Experimental Neurology 334, 113457 (2020).

63. Patel, S. D. et al. Therapeutic hypothermia and hypoxia-ischemia in the term-equivalent neonatal rat: characterization of a translational preclinical model. Pediatr. Res. 78, 264-271 (2015).

64. Waddell, J., Hanscom, M., Shalon Edwards, N., McKenna, M. C. \& McCarthy, M. M. Sex differences in cell genesis, hippocampal volume and behavioral outcomes in a rat model of neonatal HI. Exp. Neurol. 275 Pt 2, 285-295 (2016).

65. Rice, J. E., Vannucci, R. C. \& Brierley, J. B. The influence of immaturity on hypoxic-ischemic brain damage in the rat. Ann Neurol. 9, 131-141 (1981).

66. Sholl, D. A. Dendritic organization in the neurons of the visual and motor cortices of the cat. $J$. Anat. 87, 387-406 (1953).

67. Geiss, G. K. et al. Direct multiplexed measurement of gene expression with color-coded probe pairs. Nat Biotechnol 26, 317-325 (2008).

68. Miterko, L. N., Sillitoe, R. V. \& Hawkes, R. Zones and Stripes: Development of Cerebellar Topography. in Handbook of the Cerebellum and Cerebellar Disorders (eds. Manto, M., Gruol, D., Schmahmann, J., 
Koibuchi, N. \& Sillitoe, R.) 1-23 (Springer International Publishing, 2019). doi:10.1007/978-3-31997911-3_3-2.

69. Ozol, K., Hayden, J. M., Oberdick, J. \& Hawkes, R. Transverse zones in the vermis of the mouse cerebellum. J. Comp. Neurol. 412, 95-111 (1999).

70. Bradford, M. M. A rapid and sensitive method for the quantitation of microgram quantities of protein utilizing the principle of protein-dye binding. Anal. Biochem. 72, 248-254 (1976).

71. Cho, J. H. et al. Melatonin alleviates asphyxial cardiac arrest-induced cerebellar Purkinje cell death by attenuation of oxidative stress. Experimental Neurology 320, 112983 (2019).

72. Gonzalez-Perez, O., López-Virgen, V. \& Ibarra-Castaneda, N. Permanent Whisker Removal Reduces the Density of c-Fos+ Cells and the Expression of Calbindin Protein, Disrupts Hippocampal Neurogenesis and Affects Spatial-Memory-Related Tasks. Front. Cell. Neurosci. 12, 132 (2018).

\section{Figures}


(a)
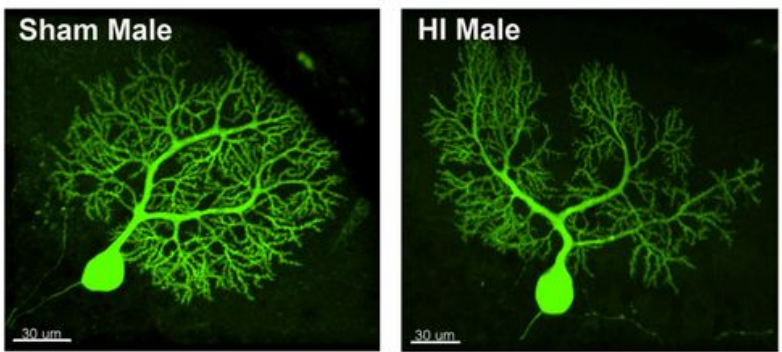

(b)

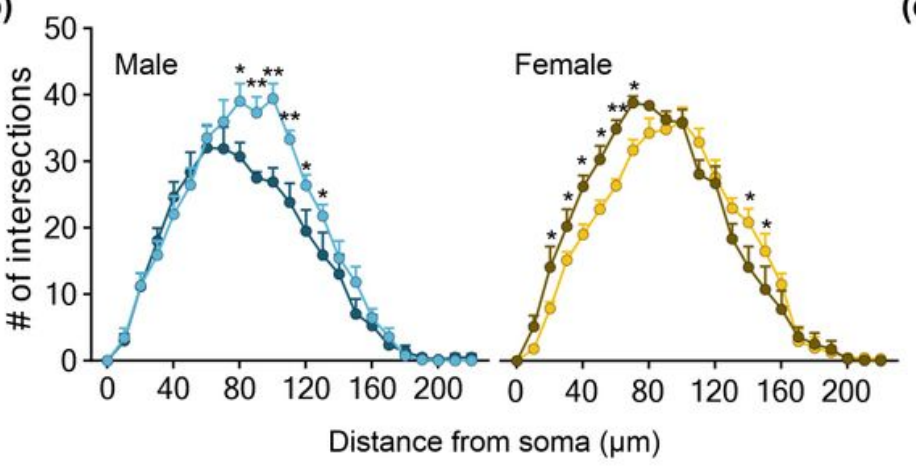

(c)

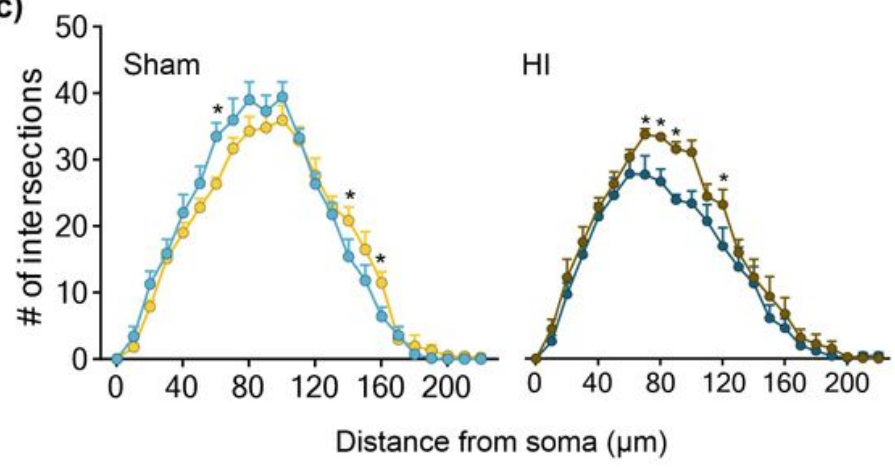

(d)

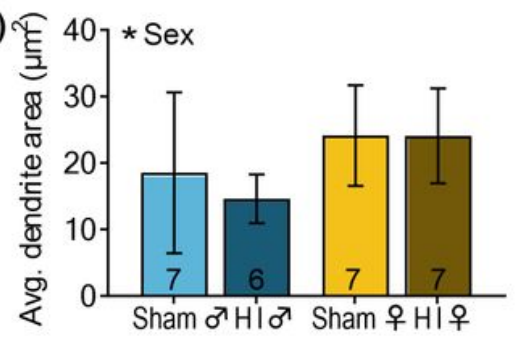

(g)

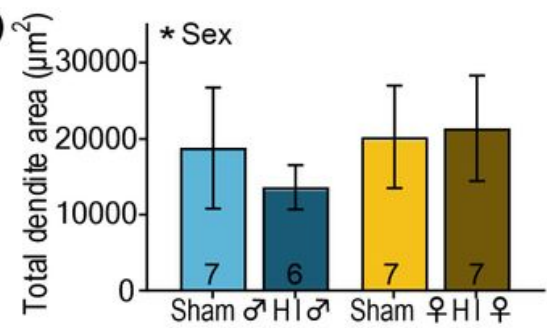

(e)

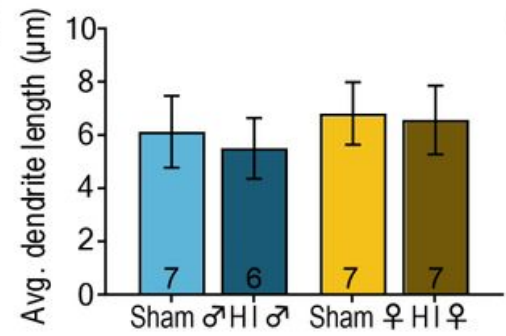

(h)

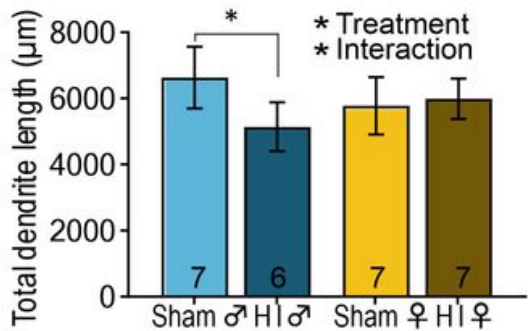

(f)

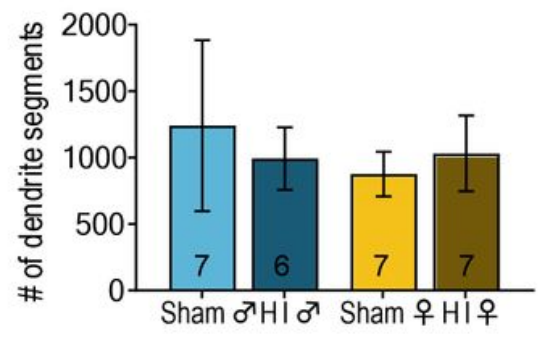

\section{Figure 1}

Lobule LVla: Purkinje neuron reconstructions and Sholl analysis. (a) Representative confocal images of male Purkinje neurons labeled with adeno-associated virus (40x magnification). (b) Sholl Analysis: HI effect in the developing vermis in males and females. (c) Sholl Analysis: sex differences in the developing vermis of sham and $\mathrm{HI}$ animals. (d) Average dendrite area. (e) Average dendrite length. (f) Number of dendrite segments. (g) Total dendrite area (h) Total dendrite length. ${ }^{*} p<0.05$ and ${ }^{*} p<0.01$; Data is shown as mean \pm SD. See Supplementary Fig. 1 for replicate data, which confirms the validity of the changes observed in Purkinje neuron morphology following $\mathrm{HI}$. 
(a)
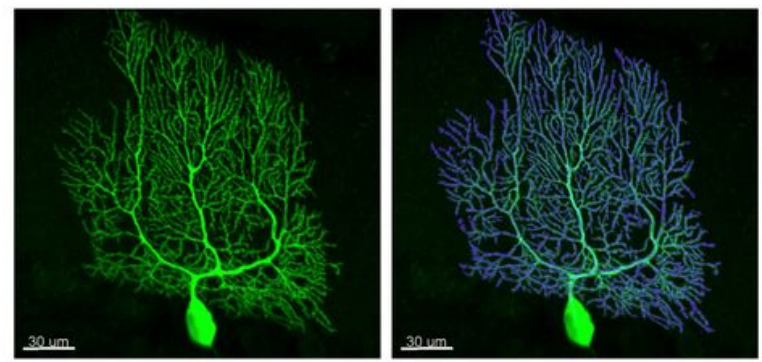

(b)

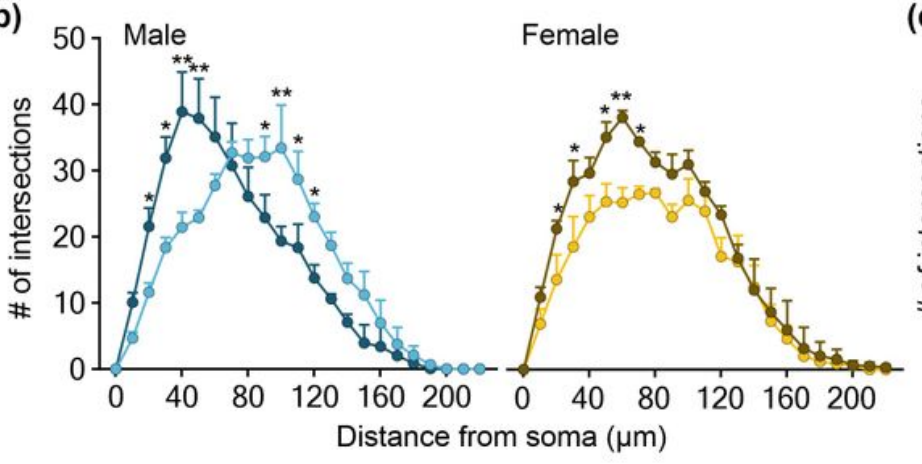

(c)

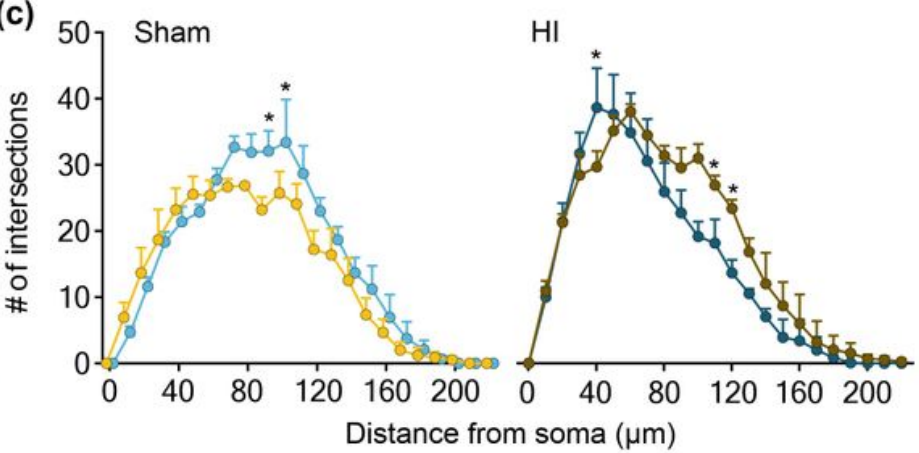

(d)

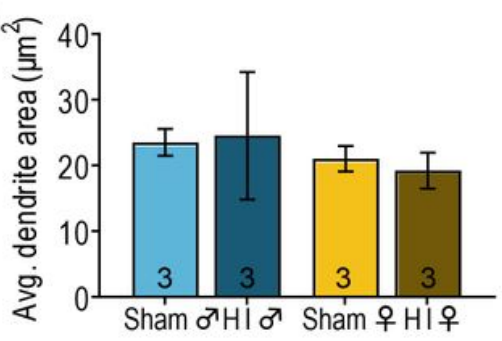

(e)

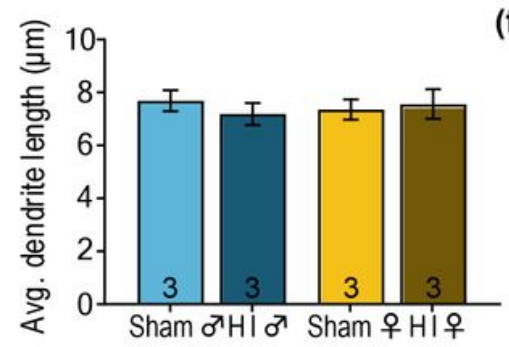

(f)

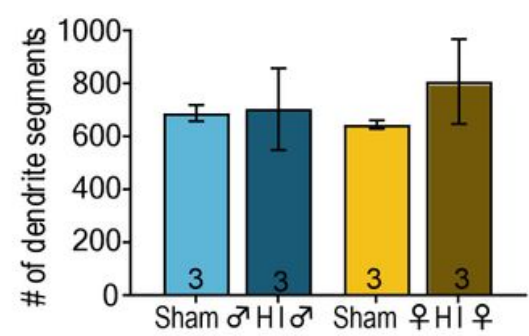

(h)

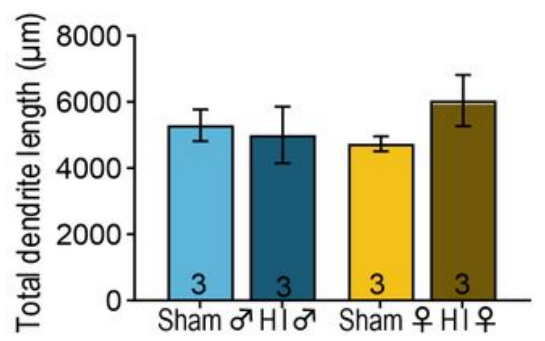

\section{Figure 2}

Lobule LX: Purkinje neuron reconstructions and Sholl analysis. (a) Confocal image of an untraced (left panel) and traced (right panel) PN17 Purkinje neuron (20x magnification). (b) Sholl Analysis: HI effect in the developing vermis in males and females. (c) Sholl Analysis: sex differences in the developing vermis of sham and $\mathrm{HI}$ animals. (d) Average dendrite area. (e) Average dendrite length. (f) Number of dendrite segments. (g) Total dendrite area. (h) Total dendrite length. ${ }^{*} p<0.05$ and ${ }^{*} \mathrm{p}<0.01$; Data is shown as mean $\pm S D$. 


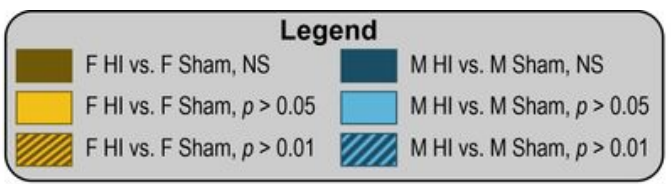

(a)

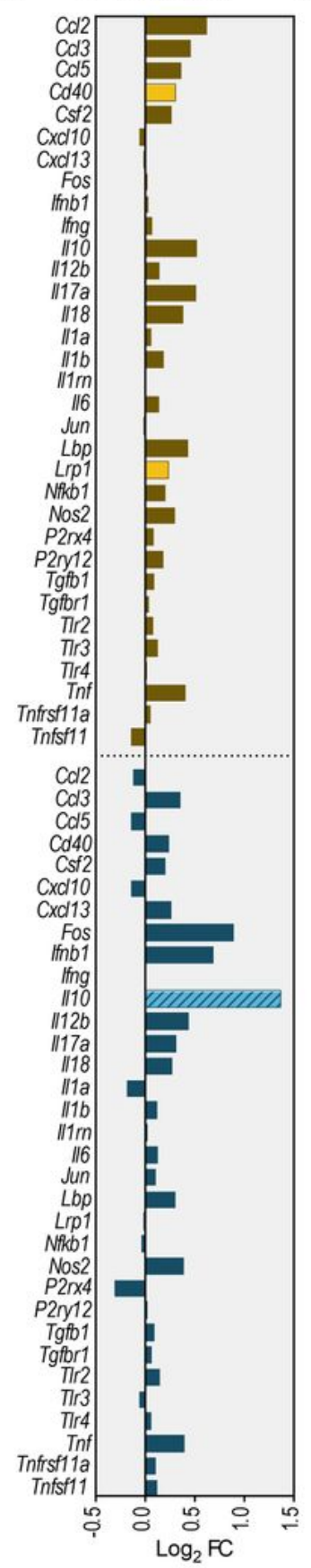

(c)

(b) Steroids \& Autacoids

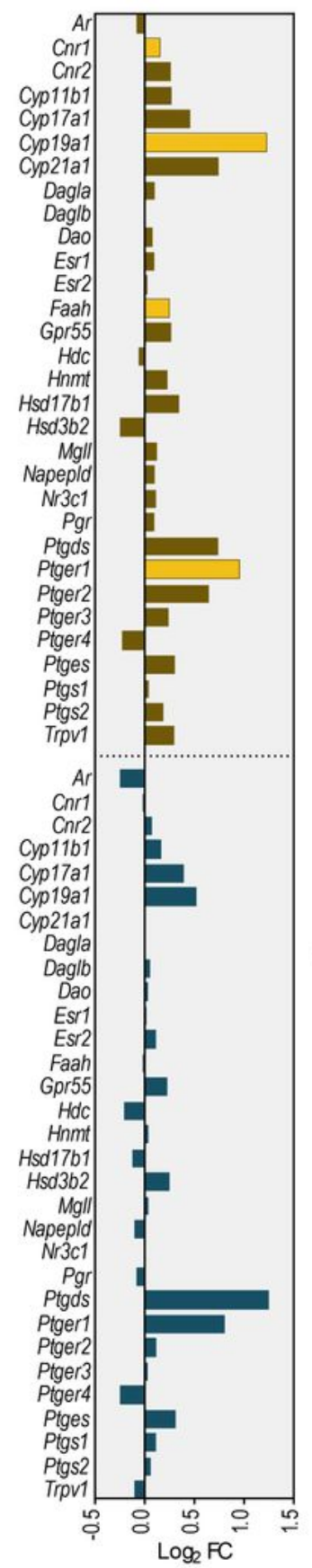

(e)

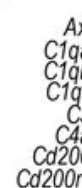

Phagocytosis

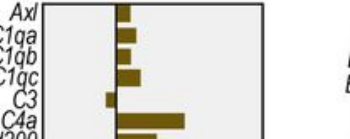

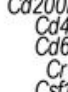
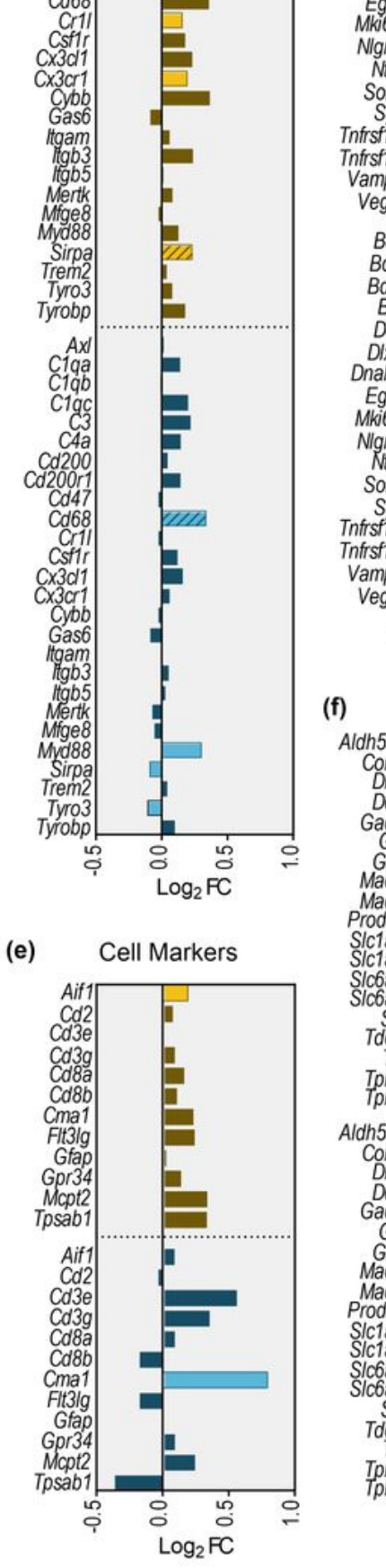

Neuro- \&

Synaptogenesis

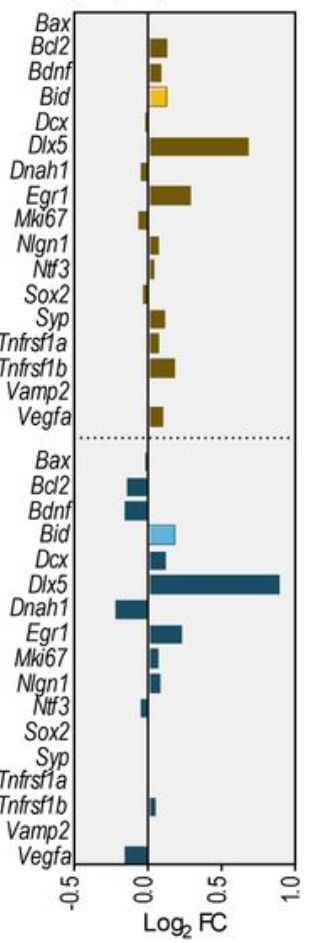

(f) Neurotransmitters

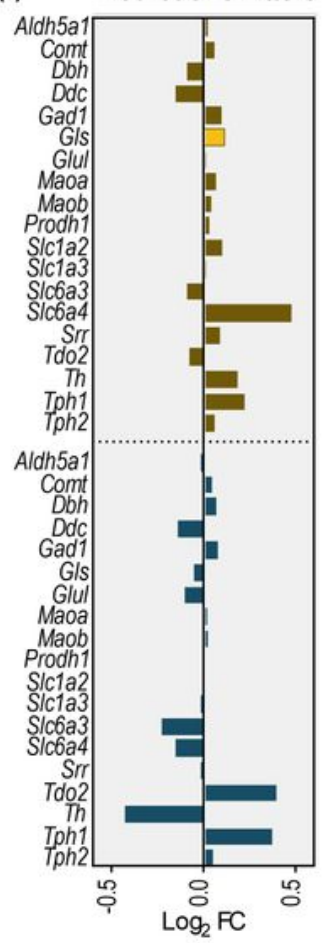

Figure 3

NanoString analysis of cerebellar vermis gene expression differentially expressed after perinatal hypoxiaischemia injury. Genes were classified in different categories as follows: (a) Genes related to Inflammation; (b) Genes related to Steroids \& Autacoids; (c) Genes related to Microglial Phagocytosis; (d) Genes related to Neurogenesis and Synaptogenesis; (e) Cell Markers; and (f) Genes related to Neurotransmitters. Legend describing representation of statistical significance is in the upper-left box. For 
analysis of genes differentially expressed in male and female cerebellar vermis (female sham vs male sham), see Supplementary Fig. 2.

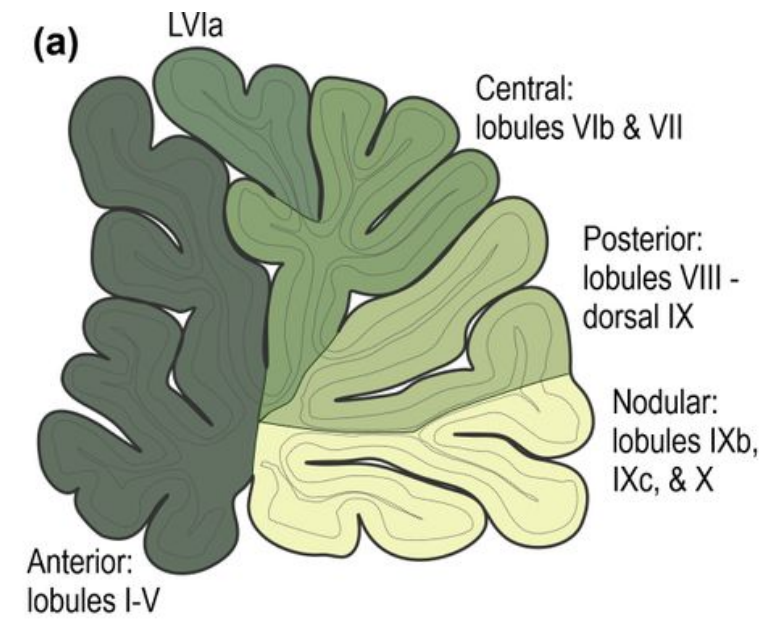

(b)

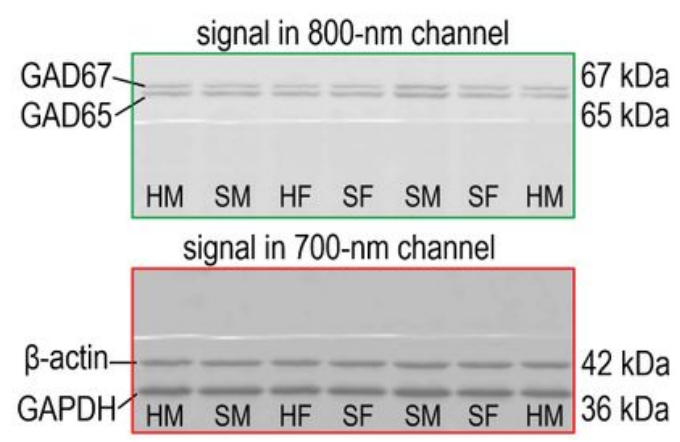

(c)

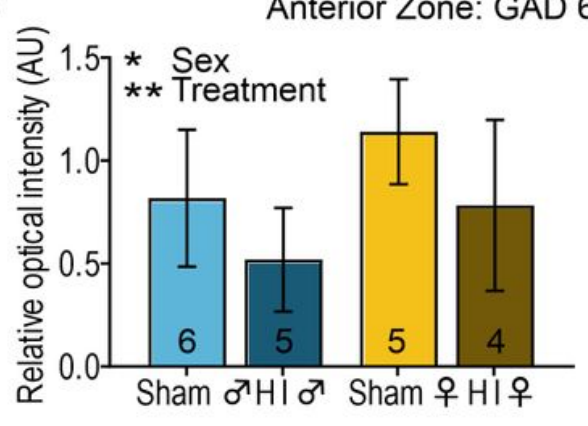

Anterior Zone: GAD 67

(e)

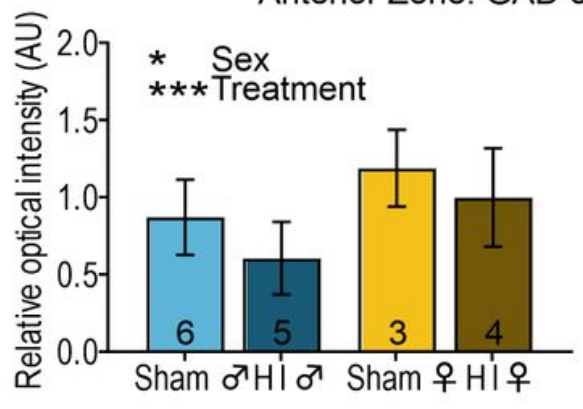

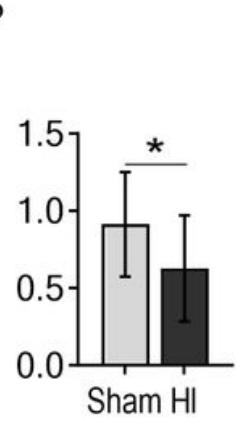

(d)

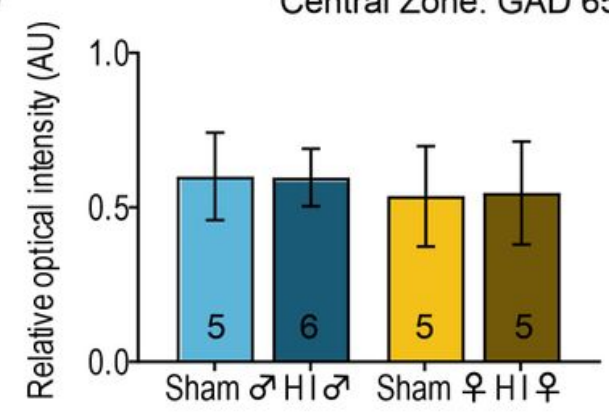

(f)

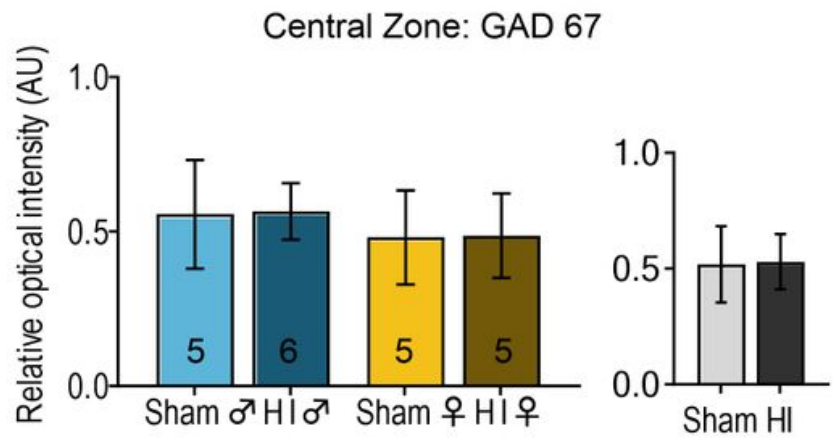

Figure 4

Western blot analysis of GAD65 and GAD67 levels in the developing vermis after HI. (a) Sagittal representation of different regions of the vermis used for analysis. (b) Representative Western blot shows GAD65 and 67 levels in the developing cerebellum of $\mathrm{HI}$ and sham animals. After initial protein transfer, the blot was cut horizontally across the molecular mass region of $50 \mathrm{kDA}$. The upper portion of the blot was incubated with antibodies that recognize glutamate decarboxylase $65 / 67$ and the bottom portion was incubated with antibodies that recognize B-actin and GAPDH. (c) HI decreased GAD65 protein levels in the anterior zone of the vermis. (d) GAD65 protein levels did not significantly change in the central zone of the vermis after HI. (e) HI decreased GAD67 protein levels in the anterior zone. (f) GAD67 protein levels 
remained the same in the central zone after $\mathrm{HI}$. In (c-f) data collapsed across sex are shown in grayscale. GAD65 = glutamate decarboxylase 65; GAD67 = glutamate decarboxylase 67; GAPDH = Glyceraldehyde3-Phosphate Dehydrogenase; $\mathrm{kDa}=$ kilodaltons; $\mathrm{HM}=\mathrm{HI}$ male; $\mathrm{HF}=\mathrm{HI}$ female; $\mathrm{SM}=$ sham male; $\mathrm{SF}=$ sham female. ${ }^{*} p<0.05,{ }^{*} p<0.01,{ }^{* \star *} p<0.001$, and $\# p=0.07 ; n=4-6$ animals /group/sex. Data is shown as mean \pm SD. Non-significant western blot data is shown in Supplementary Fig. 3 .

(a)

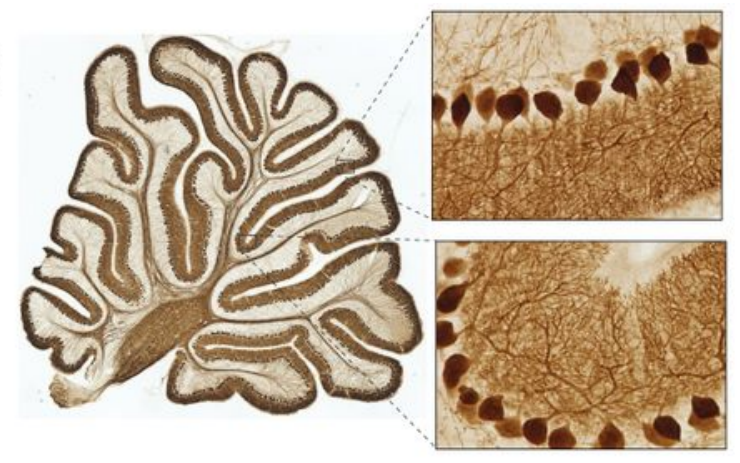

(c)

LI: CALB ${ }^{+}$soma $/ \mathrm{mm}^{2}$
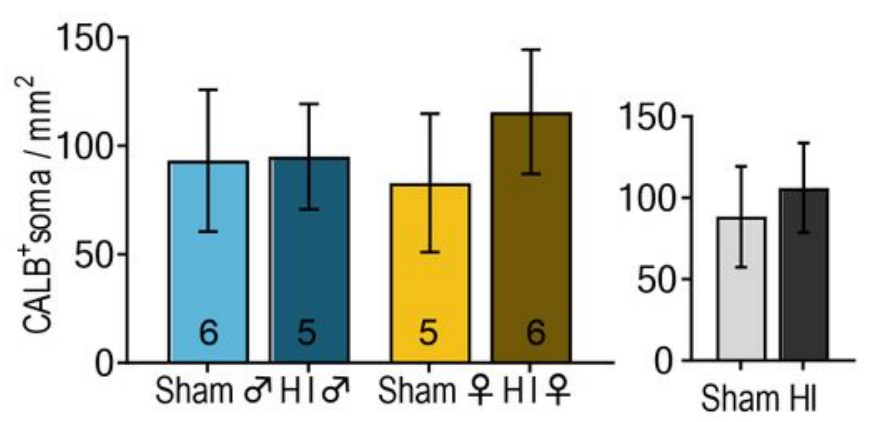

(e)

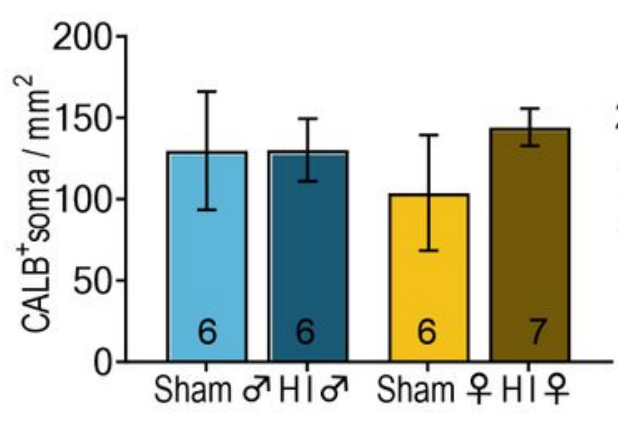

LVla: CALB ${ }^{+}$soma $/ \mathrm{mm}^{2}$

(g)

$\mathrm{LX}: \mathrm{CALB}^{+}$soma/mm

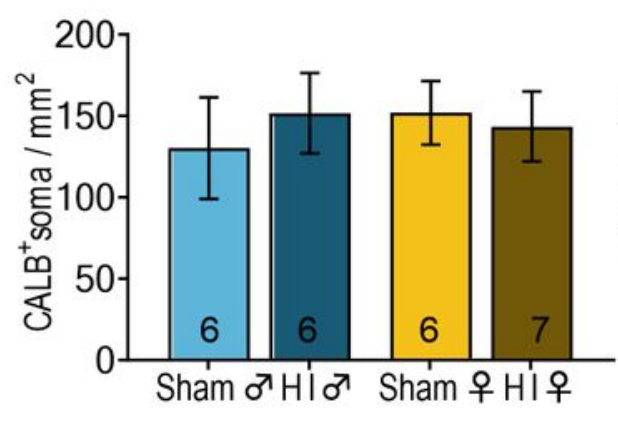

(b)

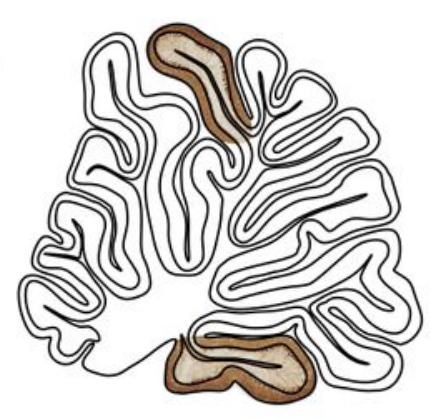

(d) LI: CALB optical density

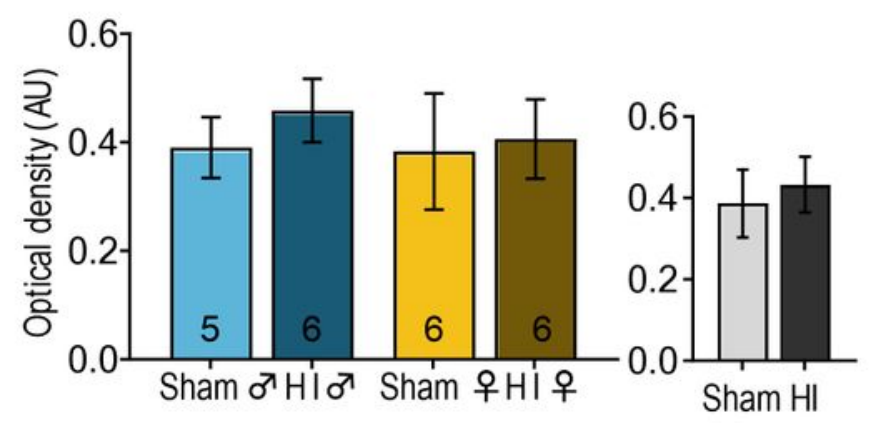

(f) LVla: CALB optical density

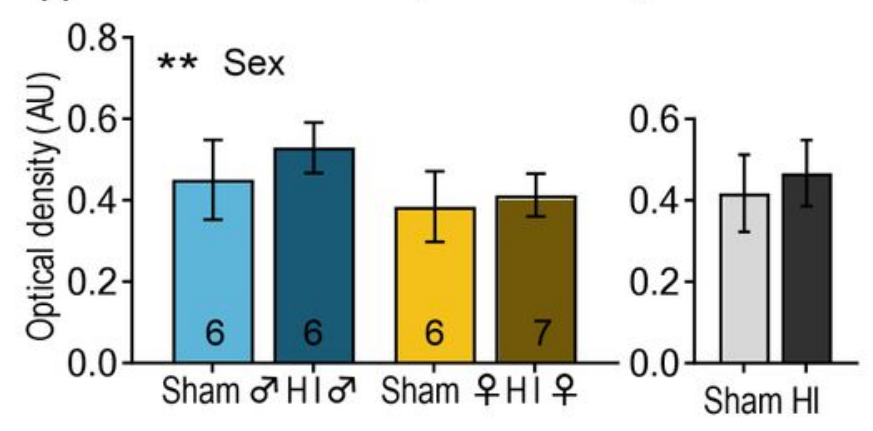

(h) LX: CALB optical density

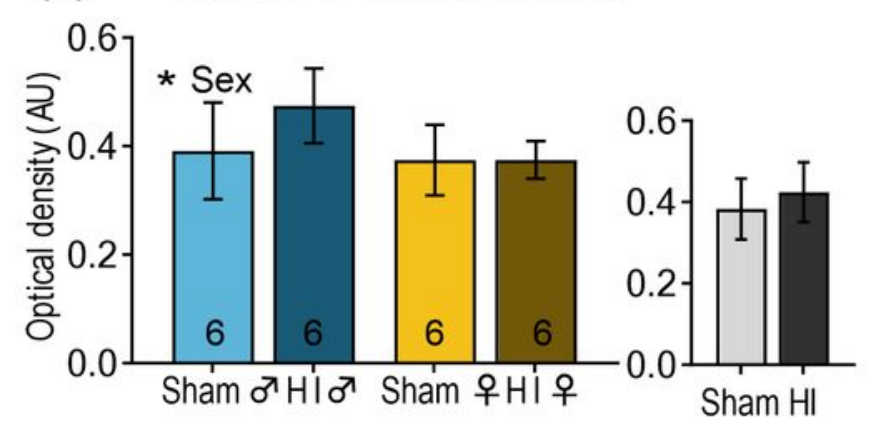

Figure 5 
Purkinje neuron analysis in the vermis. (a) Sagittal representation of the vermis stained with Calbindin (4x magnification). Insets depict higher magnification of Purkinje neurons in the posterior vermis (20x). (b) Cerebellar lobules I, Vla and X were used for morphometric and optical intensity analysis. (d) In LI, no significant differences were found after $\mathrm{HI}$ in numbers of CALB+ soma or (d) CALB optical density. (e) In cerebellar LVla, there were no significant differences found after $\mathrm{HI}$ in any of the treated groups for numbers of CALB+ somas. (f) However, optical density for CALB+ differences were found between males and females. (g) No significant differences were found after $\mathrm{HI}$ in the number of CALB+ somas for cerebellar LX, but the $(\mathrm{h})$ optical density analysis showed higher levels of CALB+ in males compared to females. In (c-h) data collapsed across sex are shfown in grayscale. ${ }^{*} p<0.05,{ }^{*} \mathrm{p}<0.01$, and $\# p=0.08$. Data is shown as mean \pm SD.

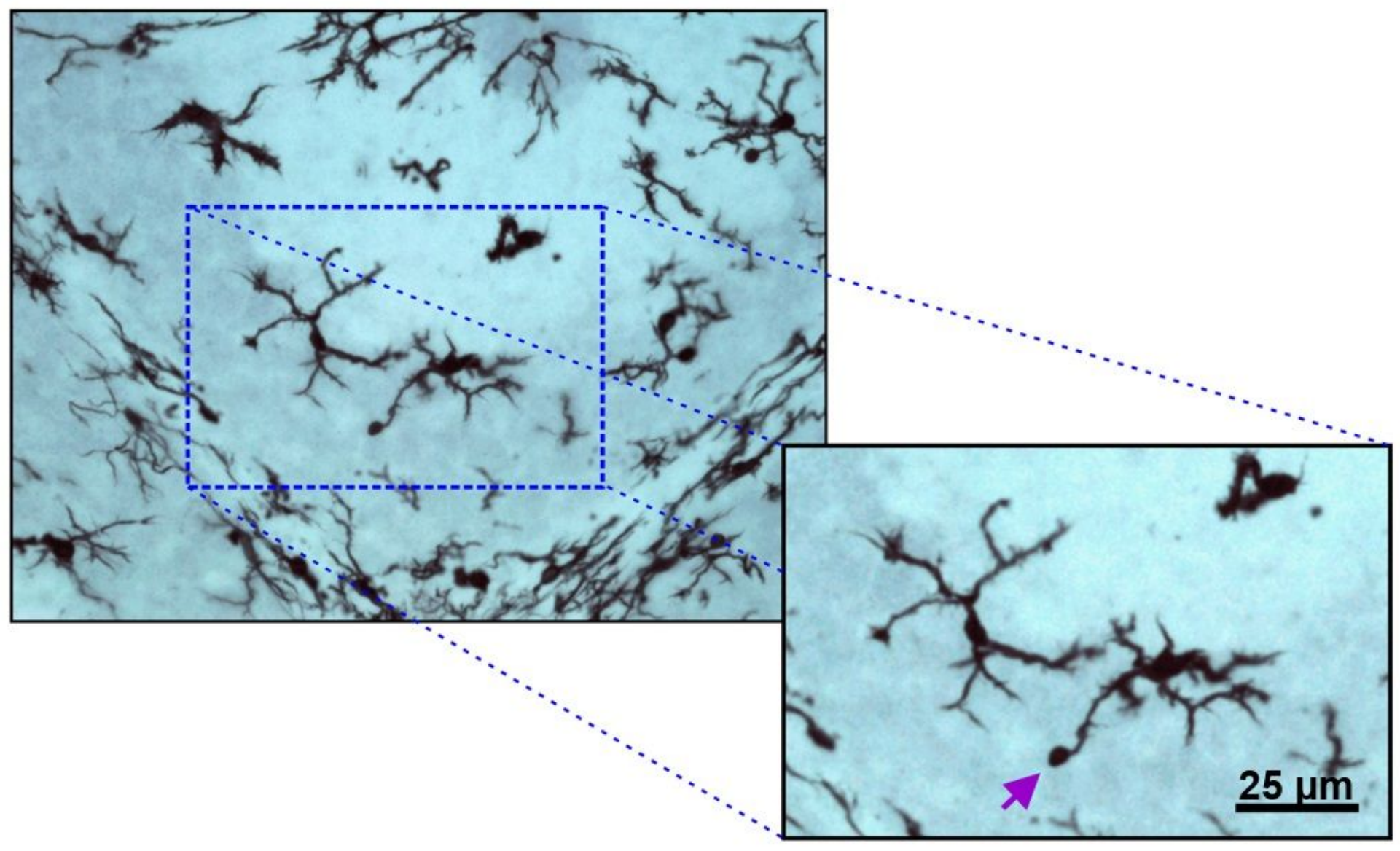

Figure 6

Microglia with and without Phagocytic Cups. Ramified microglia labeled with Iba1 in the PN17 cerebellum. On the left panel, the blue dotted rectangle shows both microglia with and without phagocytic cups (20x) in the cerebellar cortex. The right panel depicts a higher magnification (40x) of the same microglia cells with a head arrow pointing out a phagocytic cup located at the tip of a microglia process. Scale bar: $25 \mu \mathrm{m}$. 
(a)

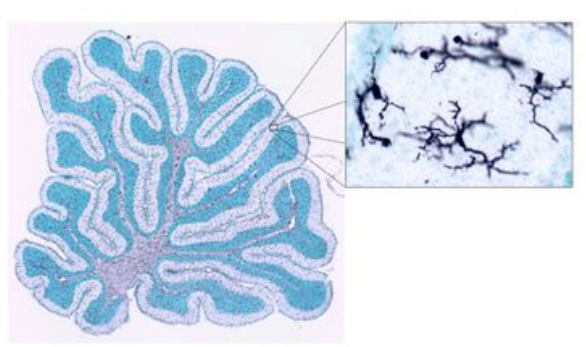

(c)

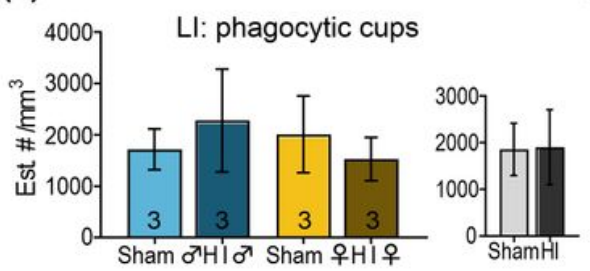

(f)

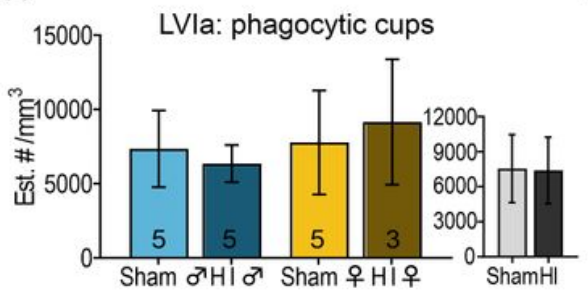

(i)

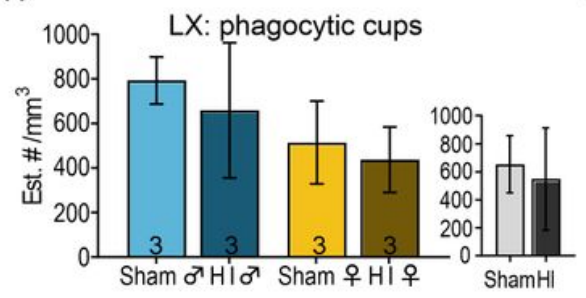

(d) (b)
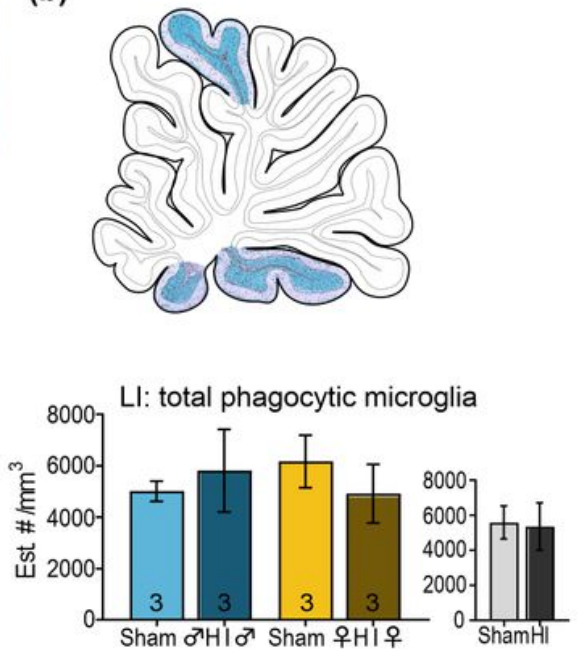

(e)

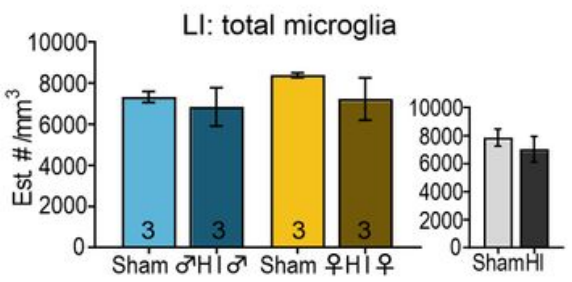

(h)
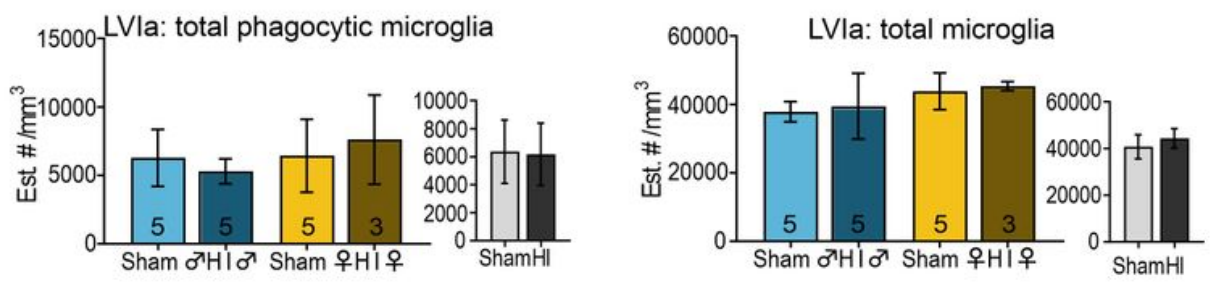

(k)

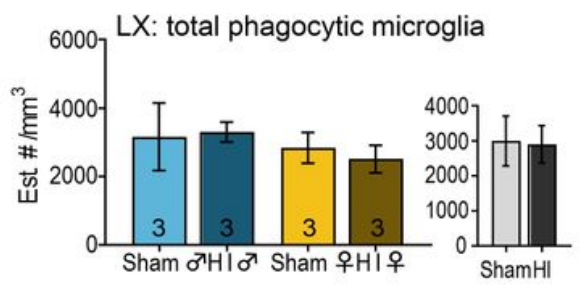

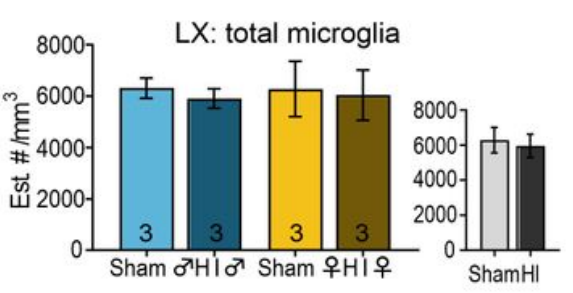

Figure 7

Phagocytic microglia analysis in the vermis. (a) Sagittal representation of the vermis stained for lba1 (DAB staining) and counterstained with methyl green (4x magnification). Insets depict a 20x magnification of Purkinje neurons in the posterior vermis. (b) Representation of cerebellar lobules I, Vla, and $\mathrm{X}$ used for analysis in Sham and $\mathrm{HI}$ animals. (c) No significant differences were found for the number of phagocytic cups, (d) the total number of phagocytic microglia, or (e) the number of total microglia in cerebellar LI. Similar results were found for the number of phagocytic cups, the total number of phagocytic microglia, or the number of total microglia in cerebellar LVla (f-h) and X (i-k), respectively. In (c-k) data collapsed across sex are shown in grayscale. Data is shown as mean \pm SD. 
(a)

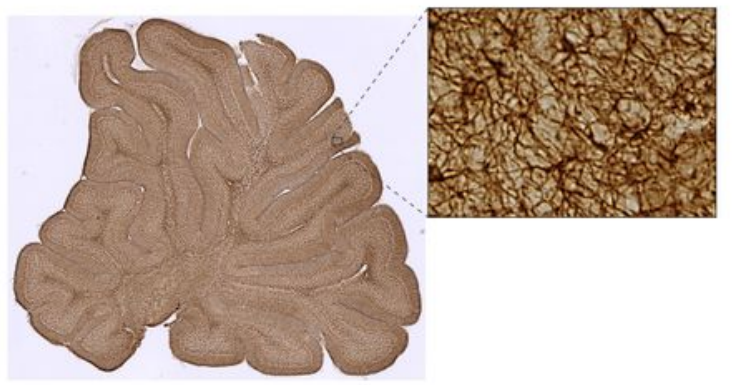

(c)

LI: GFAP soma/mm ${ }^{2}$

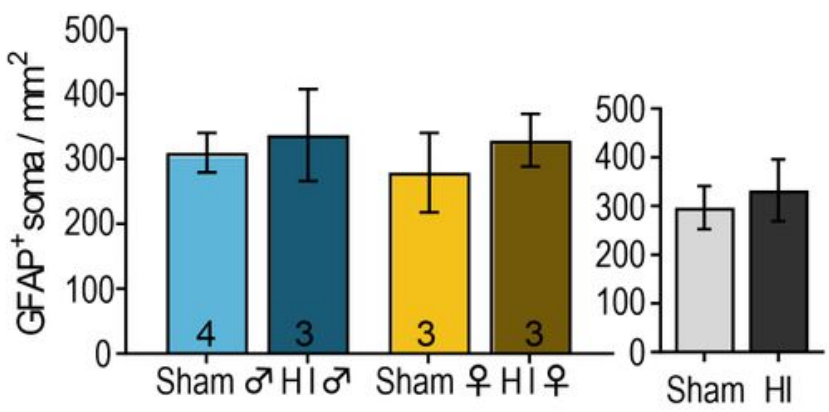

(e)

LVla: GFAP soma/mm²

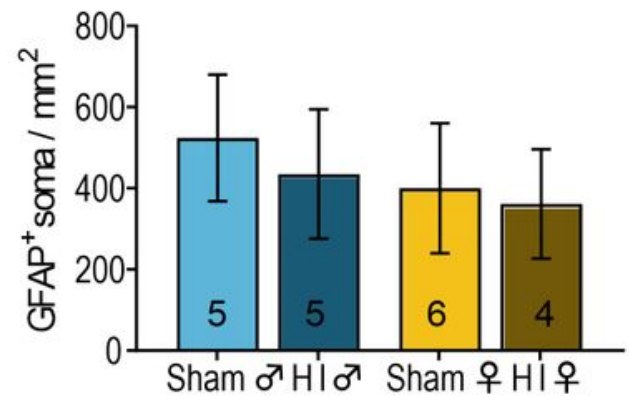

(g)

LX: GFAP soma/mm²

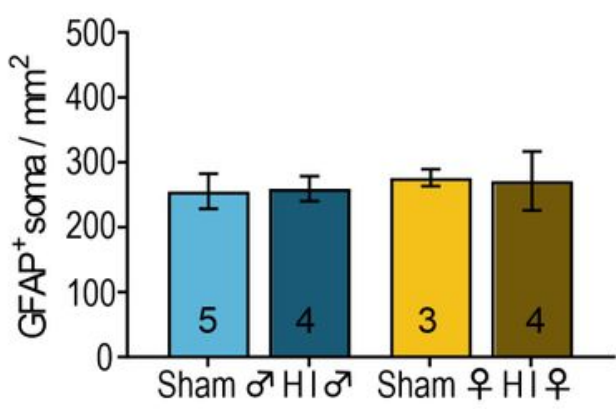

(b)

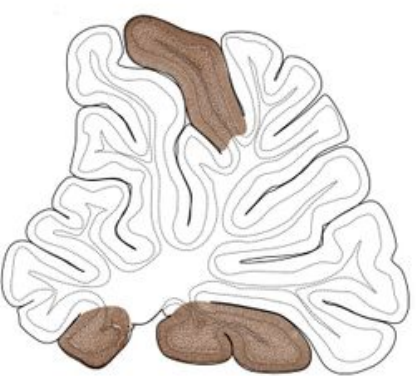

(d) LI: GFAP optical density

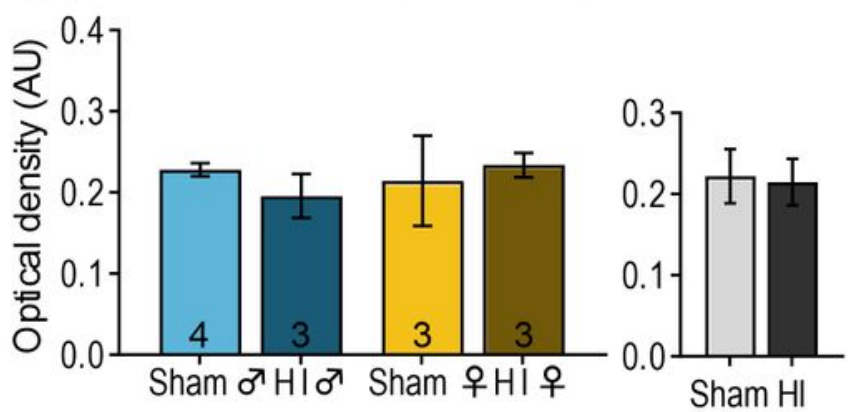

(f) LVla: GFAP optical density

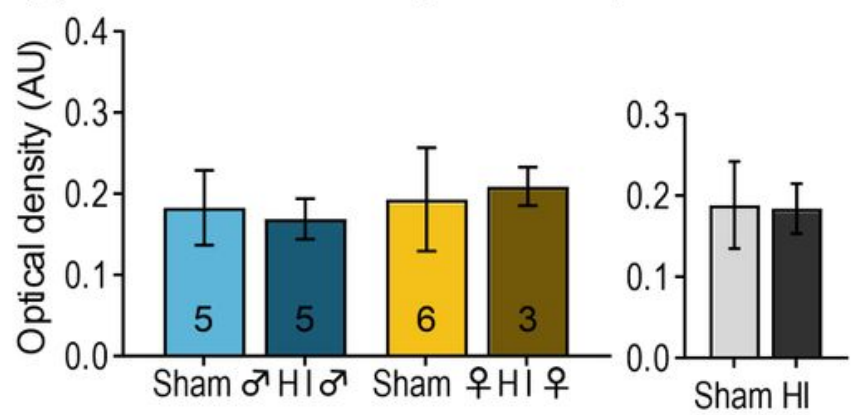

(h) LX: GFAP optical density

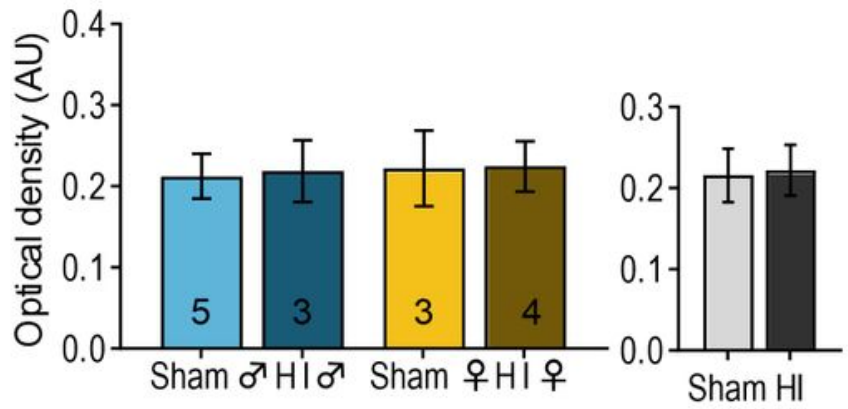

\section{Figure 8}

Astrocytes densitometric analysis in the vermis. (a) Sagittal representation of the mid-vermis stained for GFAP (DAB staining) (4x magnification). Insets show a 20x magnification of astrocytes in the posterior vermis. (b) Representation of cerebellar lobules I, Vla, and X used for morphometric in Sham and HI groups. (c) No significant differences were found for the number of GFAP+ cells or (d) the optical density 
for GFAP+ cells in cerebellar lobule I. Similar results were found in cerebellar lobules LVla $(e, f)$ and X ( $g$, h). In (c-h) data collapsed across sex are shown in grayscale. Data is shown as mean \pm SD.
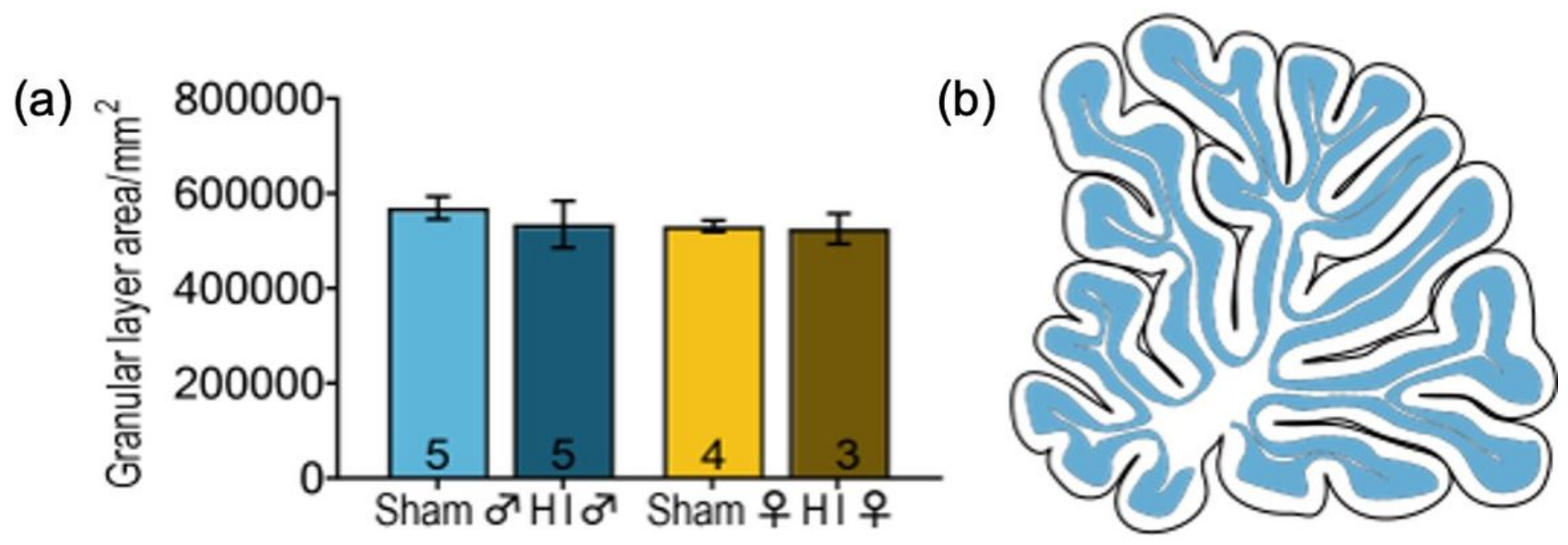

Figure 9

Granular layer area analysis. (a) HI did not change the area of the granular layer (GL) in any of the treated groups in males or females. (b) Sagittal representation of the mid-vermis stained for cresyl violet showing the GL of the cerebellar cortex used for the area analysis. Data is shown as mean \pm SD.

\section{Supplementary Files}

This is a list of supplementary files associated with this preprint. Click to download.

- SupplementaryFigCOMBINED.docx 